\title{
THE EFFECT OF ALCOHOL AND BITTERNESS LEVELS ON BREWING YEAST VIABILITY
}

\author{
A Thesis \\ presented to \\ the Faculty of California Polytechnic State University, \\ San Luis Obispo
}

\begin{abstract}
In Partial Fulfillment
of the Requirements for the Degree

Master of Science in Agriculture, Specialization in Food Science and Nutrition
\end{abstract}

by

Nichole Elizabeth Bryant

March 2019 
(C) 2019

Nichole Elizabeth Bryant

ALL RIGHTS RESERVED 
TITLE: The Effect of Alcohol and Bitterness Levels on Brewing Yeast Viability

AUTHOR: Nichole Elizabeth Bryant

DATE SUBMITTED: $\quad$ March 2019

COMMITTEE CHAIR: Luis Castro, $\mathrm{PhD}$

Assistant Professor of Food Science

COMMITTEE MEMBER: Amanda Lathrop, PhD

Associate Professor of Food Science

COMMITTEE MEMBER: $\quad$ Federico Cassasa, PhD

Assistant Professor of Enology 


\author{
ABSTRACT \\ The Effect of Alcohol and Bitterness Levels on Brewing Yeast Viability \\ Nichole Elizabeth Bryant
}

Two of the most popular beer styles within the craft brewing industry are India Pale Ales (IPA's) and those with high alcohol by volume (ABV). Production of these styles requires high gravity fermentation and high amounts of bittering hops in order to reach the required values for $\mathrm{ABV}$ and International Bitterness units (IBU) respectively. The aim of this study was to determine the impact of high gravity fermentation and high IBU levels on yeast viability and repitching cycles.

An initial experiment on high gravity fermentations was done in order to assess the effects this variable had alone. Successive five day fermentations employing serial repitching were performed on worts with low $\left(10^{\circ} \mathrm{P}\right)$, medium $\left(14{ }^{\circ} \mathrm{P}\right)$, and high $\left(18{ }^{\circ} \mathrm{P}\right)$ gravity levels. The minimum viability for repitching established for this study was $85 \%$. Once the viability of a sample fell below this minimum, it would not be suitable for repitching. It was found that increasing gravity level led to lower viabilities at the end of the fermentation period. Viability decreased further as fermentation generation increased for the high gravity samples. Yeast harvested from low gravity fermentations could be repitched up to eight times. Medium and high gravity fermentations could be repitched up to five times.

This study was repeated at single gravity levels with low (25), medium (50) and high (75) IBU levels. A loss in viability with increased IBU levels over serial re-pitching cycles in the low gravity wort $\left(10^{\circ} \mathrm{P}\right)$ was observed. It was found that at the low gravity level, yeast could be repitched eight times at the low IBU level, five times at the medium IBU level, and four times at the high IBU level.

When the experiment was repeated with medium and high gravity worts, the results indicated that the compound effects of increased gravity and IBU levels significantly reduced yeast viability throughout re-pitching cycles and thus limits the number of times that this yeast could be reused when compared to low gravity and low IBU fermentations. Medium gravity fermentations could be repitched three times at the low IBU level and twice at the medium and high IBU levels. High gravity fermentations could be repitched three times at all IBU levels. 


\section{ACKNOWLEDGMENTS}

I would like to thank the Food Science department at Cal Poly San Luis Obispo for this opportunity and the CSU-ARI for funding on this project. I wish to thank my family for their support through graduate school, especially my parents Eric and Toni Bryant, my sister Kerri Bryant, and my grandmother Sylvia Bocchario. Thank you to my grandfather Papa "HoHo". Thank you to my undergraduate advisor, Dr. Jackie Trischman for believing in me and inspiring me to further my studies with graduate school. Thank you Dr. Amin for the encouragement and wonderful food.

I would like to thank Firestone Walker, Barrelhouse, and Barth-Haas group for their donation of materials to this project. I would also like to thank Dr. Reeves from the Nutrition department for lending me his UV/Vis spectrometer. Thank you to Dr. Smith from the Statistics department for assisting me with the analysis portion of this study.

Finally, I would like to thank the friends that I made in this short time and my lovely laboratory assistants, Ashley Pickens and Catalina Ramirez. Thank you to the Pink Boots Society for showing me how incredible women in the brewing industry are. Last but certainly not least, I would like to thank my cat Pinky. 


\section{TABLE OF CONTENTS}

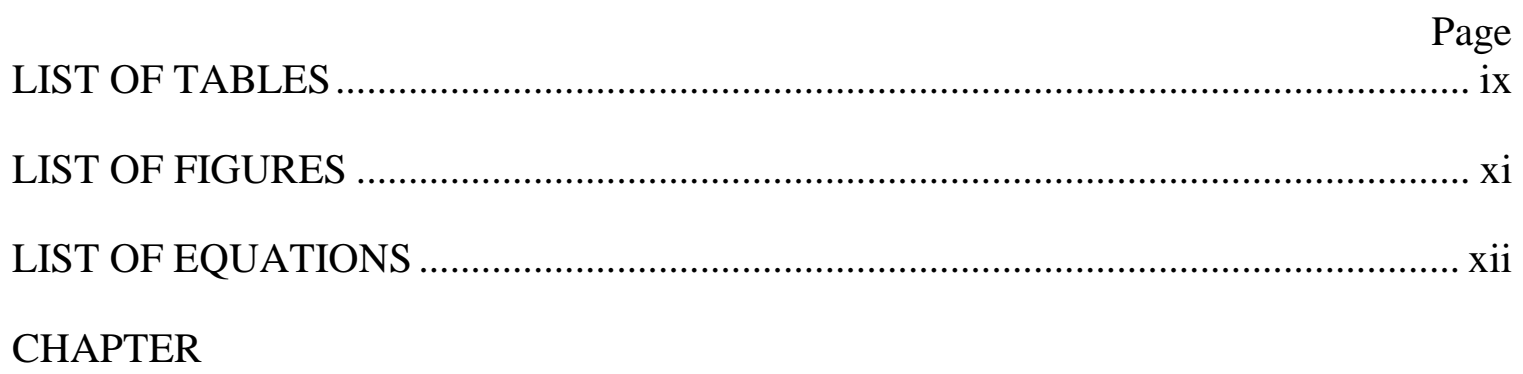

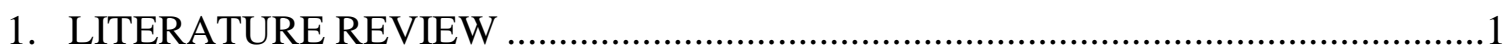

1.1. Anthropological aspects of beer and brewing ......................................... 1

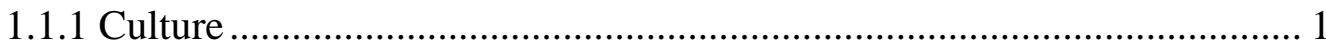

1.1.2 Industry and market growth ...................................................... 3

1.2 Raw materials and the brewing process .................................................. 3

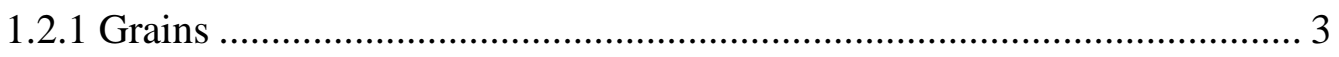

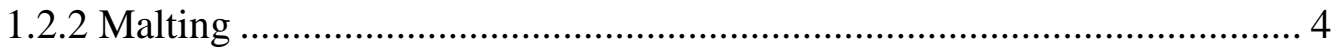

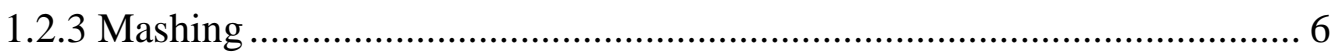

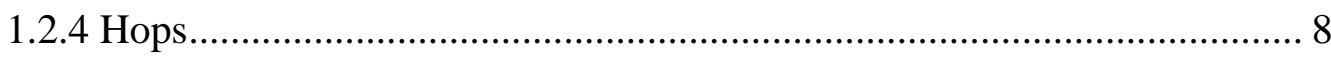

1.2.4.1 Alpha-acids and isomerization.......................................... 8

1.2.4.2 International bitterness units ................................................ 10

1.2.4.3 Additional hop flavor attributes ........................................ 11

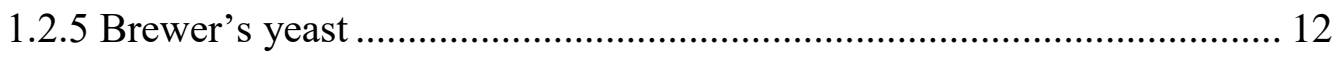

1.2.5.1 Life cycle .................................................................... 14 


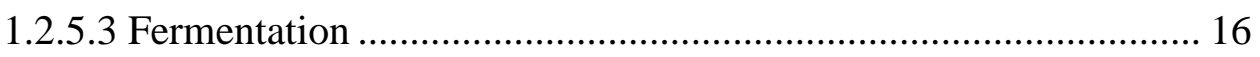

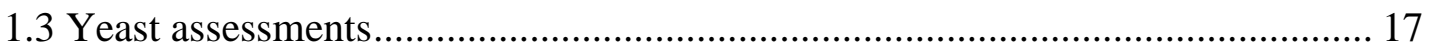

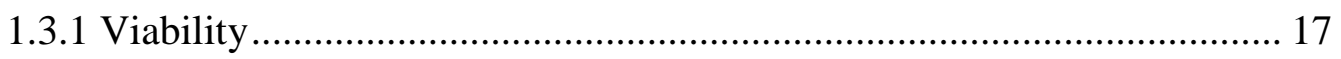

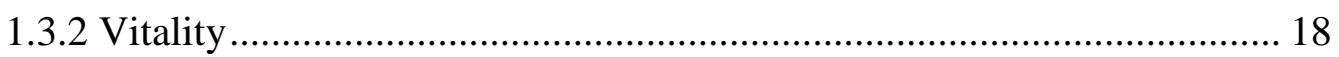

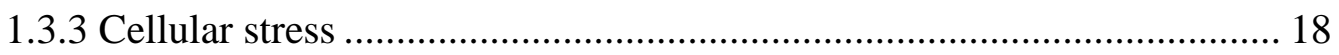

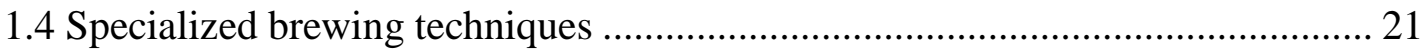

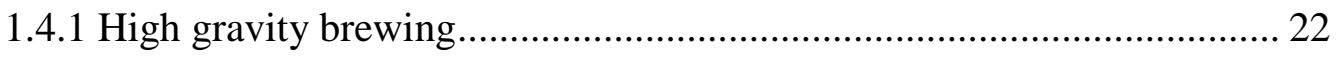

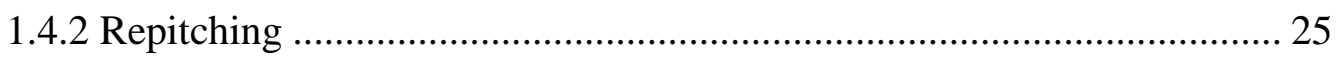

1.4.3 Combining repitching and high gravity fermentations........................... 27

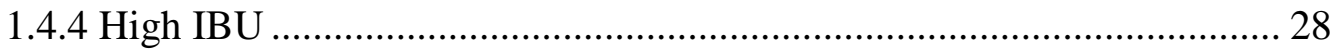

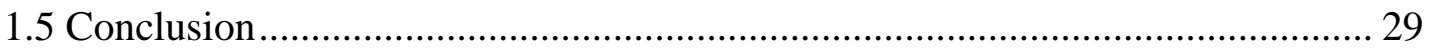

2. THE EFFECT OF ALCOHOL AND BITTERNESS LEVELS ON BREWING

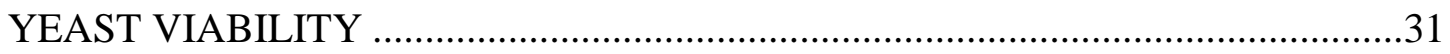

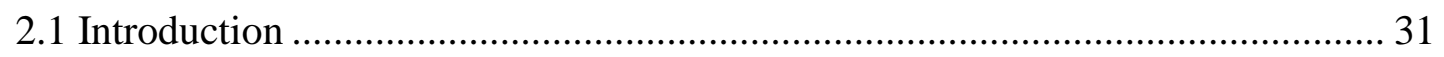

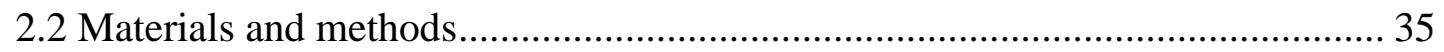

2.2.1 Yeast propagation ................................................................................. 35

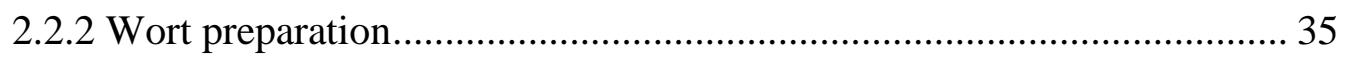

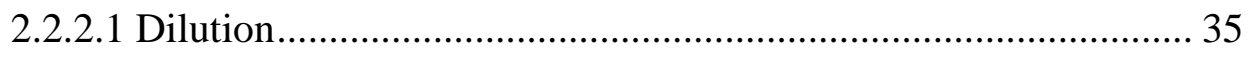

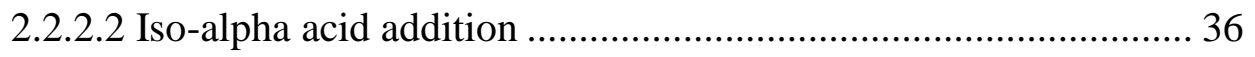


2.2.3 Fermentation conditions 38

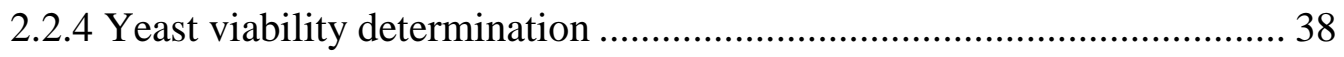

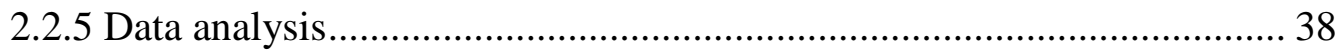

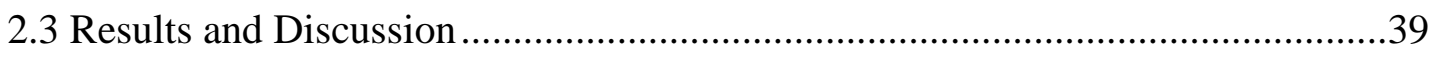

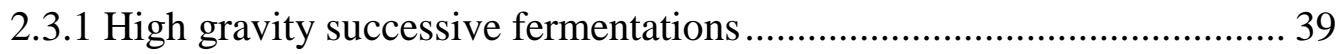

2.3.1.1 Effect of high gravity successive fermentations on apparent attenuation ................................................................ 39

2.3.1.1 Effect of high gravity successive fermentations on yeast

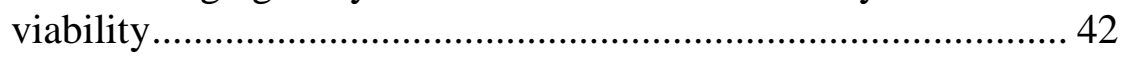

2.3.1.3 Alcohol by volume of high gravity successive fermentations .... 44

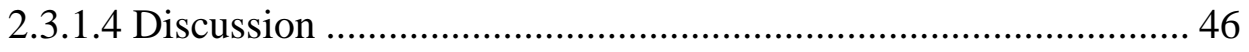

2.3.2 High IBU and high gravity successive fermentations ............................. 47

2.3.2.1 Effect of high IBU and high gravity successive fermentations on apparent attenuation .............................................................. 47

2.3.2.2 Effect of high IBU and high gravity successive fermentations

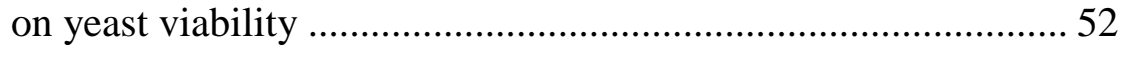

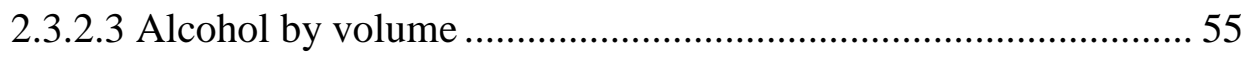

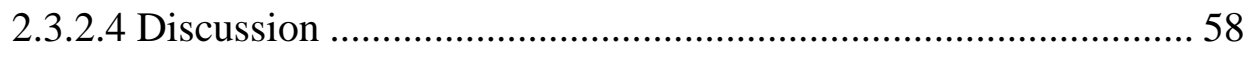

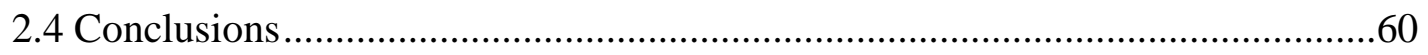

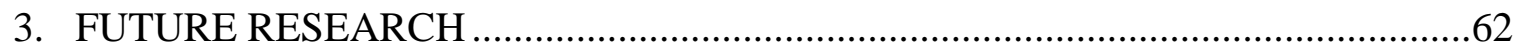

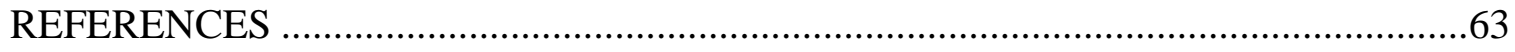

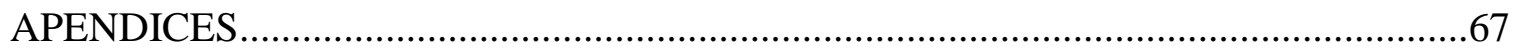




\section{LIST OF TABLES}

Table

Page

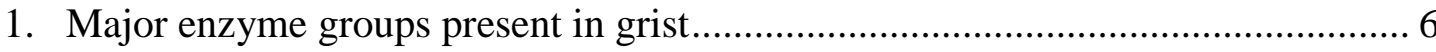

2. Volume of Isohop added for each of the IBU levels. ..................................... 37

3. Viability (\%) of Saccharomyces cerevisiae after 5 days of fermentation at $21^{\circ} \mathrm{C}$ with low $\left(10^{\circ} \mathrm{P}\right)$ medium $\left(14^{\circ} \mathrm{P}\right)$ and high $\left(18^{\circ} \mathrm{P}\right)$ initial gravities.

4. Alcohol by volume (\%) of Saccharomyces cerevisiae after 5 days of fermentation at $21^{\circ} \mathrm{C}$ with low $\left(10^{\circ} \mathrm{P}\right)$ medium $\left(14^{\circ} \mathrm{P}\right)$ and high $\left(18{ }^{\circ} \mathrm{P}\right)$ initial gravities

5. Viability (\%) of Saccharomyces cerevisiae after 5 days of low gravity $\left(10^{\circ} \mathrm{P}\right)$ fermentations at $21^{\circ} \mathrm{C}$ with low (25) medium (50) and high (75) IBU treatments.

6. Viability (\%) of Saccharomyces cerevisiae after 5 days of medium gravity $\left(14{ }^{\circ} \mathrm{P}\right.$ ) fermentations at $21^{\circ} \mathrm{C}$ with low (25) medium (50) and high (75) IBU treatments.

7. Viability (\%) of Saccharomyces cerevisiae after 5 days of high gravity ( $\left.18{ }^{\circ} \mathrm{P}\right)$ fermentations at $21^{\circ} \mathrm{C}$ with low (25) medium (50) and high (75) IBU treatments.

8. Alcohol by volume (\%) of Saccharomyces cerevisiae after 5 days of low gravity $\left(10^{\circ} \mathrm{P}\right)$ fermentations at $21^{\circ} \mathrm{C}$ with low (25) medium (50) and high (75) IBU treatments 56

9. Alcohol by volume (\%) of Saccharomyces cerevisiae after 5 days of medium gravity $\left(14^{\circ} \mathrm{P}\right)$ fermentations at $21^{\circ} \mathrm{C}$ with low (25) medium (50) and high (75) IBU treatments

10. Alcohol by volume (\%) of Saccharomyces cerevisiae after 5 days of high gravity $\left(18{ }^{\circ} \mathrm{P}\right)$ fermentations at $21^{\circ} \mathrm{C}$ with low (25) medium (50) and high (75) IBU treatments

11. Repitching recommendations for low $\left(10^{\circ} \mathrm{P}\right)$, medium $\left(14^{\circ} \mathrm{P}\right)$ and high $\left(18^{\circ} \mathrm{P}\right)$ starting gravity fermentations with low (25) medium (50) and high (75) IBU treatments 
A1.Recorded initial gravities of fermentations with target low $\left(10^{\circ} \mathrm{P}\right)$ medium $\left(14^{\circ} \mathrm{P}\right)$ and high $\left(18^{\circ} \mathrm{P}\right)$ initial gravities.

A2. Recorded initial gravities with target low $\left(10^{\circ} \mathrm{P}\right)$ medium $\left(14^{\circ} \mathrm{P}\right)$ and high $\left(18^{\circ} \mathrm{P}\right)$ initial gravities and low (25) medium (50) and high (75) IBU treatments

A3. Recorded IBU values with targets of low (25), medium (50), and high (75) IBU and low $\left(10^{\circ} \mathrm{P}\right)$ medium $\left(14^{\circ} \mathrm{P}\right)$ and high $\left(18^{\circ} \mathrm{P}\right)$ initial gravities.

A4.Apparent attenuation (\%) of Saccharomyces cerevisiae after 5 days of fermentation at $21^{\circ} \mathrm{C}$ with low $\left(10^{\circ} \mathrm{P}\right)$ medium $\left(14^{\circ} \mathrm{P}\right)$ and high $\left(18^{\circ} \mathrm{P}\right)$ initial gravities

A5.Apparent attenuation (\%) of Saccharomyces cerevisiae after 5 days of low gravity $\left(10^{\circ} \mathrm{P}\right)$ fermentations at $21^{\circ} \mathrm{C}$ with low (25) medium (50) and high (75) IBU treatments

A6.Apparent attenuation (\%) of Saccharomyces cerevisiae after 5 days of medium gravity $\left(14^{\circ} \mathrm{P}\right)$ fermentations at $21^{\circ} \mathrm{C}$ with low (25) medium (50) and high (75) IBU treatments

A7.Apparent attenuation (\%) of Saccharomyces cerevisiae after 5 days of high gravity $\left(18^{\circ} \mathrm{P}\right)$ fermentations at $21^{\circ} \mathrm{C}$ with low (25) medium (50) and high (75) IBU treatments 


\section{LIST OF FIGURES}

Figure $\quad$ Page

1. The mechanism of alpha-acid isomerization to iso-alpha acids. ......................... 9

2. Apparent attenuation of Saccharomyces cerevisiae after five day successive fermentations with low $\left(10^{\circ} \mathrm{P}\right)$ medium $\left(14^{\circ} \mathrm{P}\right)$ and high $\left(18^{\circ} \mathrm{P}\right)$ initial gravities.

3. Apparent attenuation of Saccharomyces cerevisiae after five day successive low gravity fermentations $\left(10^{\circ} \mathrm{P}\right)$ with low (25) medium (50) and high (75) IBU treatments

4. Apparent attenuation of Saccharomyces cerevisiae after five day successive medium gravity $\left(14^{\circ} \mathrm{P}\right)$ fermentations with low (25) medium (50) and high (75) IBU treatments

5. Apparent attenuation of Saccharomyces cerevisiae after five day successive high gravity $\left(18^{\circ} \mathrm{P}\right)$ fermentations with low (25) medium (50) and high (75) IBU treatments 


\section{LIST OF EQUATIONS}

$\begin{array}{ll}\text { Equation } & \text { Page }\end{array}$

1. Bitterness measured as absorbance.................................................................. 10

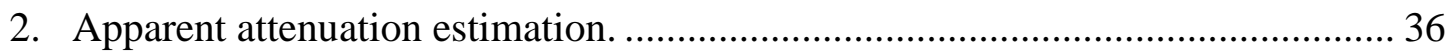

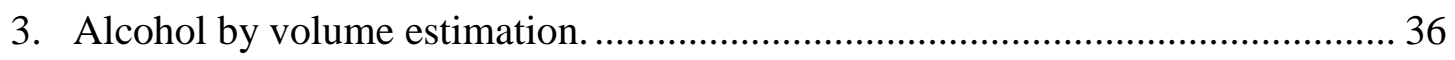

4. Volume of Isohop for desired IBU level............................................................. 37

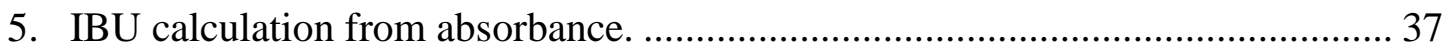




\section{LITERATURE REVIEW}

\subsection{Anthropological aspects of beer and brewing}

\subsubsection{Culture}

Beer is a complex fermented beverage that has carried significance throughout the course of human history. It is largely believed that beer was an accidental discovery through the spoilage of bread or grain. Mesopotamian cuneiform tablets at least five thousand years old have been found detailing a rich culture surrounding brewing practices. It is estimated that approximately forty percent of Mesopotamian cereal crops were utilized for brewing. Beer became a dietary staple and was the primary beverage consumed in Ancient Egypt among all social classes; providing both a sterile water source and an acceptable form of administering medicinal herbs. The addition of herbs provided flavor while also extending the life of the beverage through inhibition of microbial growth (Barth, 2013).

The practice of brewing evolved alongside civilization, eventually reaching the Germanic people and parts of the world now known as Europe. Thereafter, Bavarian monks contributed greatly to the growth of brewing techniques. The lagering technique, or cold conditioning, was developed in German monasteries. Beer barrels were stored in cellars and conditioned over the winter months, this resulted in selective breeding of yeast with certain qualities such as withstanding lower temperatures and longer fermentation times (Boulton et al., 2006). 
A notable style that arose during the $18^{\text {th }}$ century was the India Pale Ale (IPA). British soldier outposts in India increased their demand for beer. However, it spoiled quickly during transportation around the Indian Peninsula. The solution was to greatly increase the alcohol and hop content. These additions reduced the risk of infection from spoilage microorganisms and also provided a unique and extremely bitter flavor profile (Jurado, 2002).

Early colonists to the Americas brought with them their appreciation for beer and the brewing practice. Walter Raleigh is noted for introducing brewing yeast to the Virginia settlements in North America (Boulton et al., 2006). The influx of German immigrants of the early to mid-1800's included familiar names such as Anheuser-Bush, Miller, and Best. These families were the first to establish breweries in the United States (Oggle, 2006). The American beer industry flourished, surviving wars and depressions, and eventually became the multi-billion dollar industry it is today (Brewers Association, 2017).

The alcoholic brew has inspired scientific advancements, societal traditions, as well as laws and legislations. The Bavarian purity order in 1516, Reinheistgebot, declared that he only ingredients acceptable in beer production were barley, water, and hops (Barth, 2013). This predates the understanding of the importance yeast has in brewing. This knowledge came with the discoveries of Louis Pasteur in the 1800's which established that fermentation was a microbial and not a spontaneous process. The measurement of $\mathrm{pH}$, specific gravity, and the invention of the thermometer are additional advancements made because of brewing (Boulton et al., 2006). 


\section{$\underline{1.1 .2 \text { Industry and market growth }}$}

Almost 200 million barrels (6.2 billion gallons) of beer are produced annually in the United States. The overall market is worth over $\$ 100$ billion dollars. These figures include large scale industrial breweries as well as craft and microbreweries. The key difference between craft and industrial brewing is volume of production. The Brewers Association defines craft breweries as independently owned, with a volume of production of 6 million barrels (186 million gallons) of beer or less each year. In total, the craft breweries in the United States produce 24.5 million barrels annually and contribute $12.3 \%$ of the total market (Brewers association, 2017).

The United States has experienced a craft beer revival since the 1970's and through it has gained a thirst for good quality and highly hopped beers. Between 2012 and 2016, the number craft breweries operating in the United States has more than doubled from 2,420 to 5,234. The growth from 2015 and 2016 alone was an increase of $730(16.2 \%)$ craft breweries (Brewers association, 2017).Within this market, the craft India Pale Ale (IPA) style is by far the most popular brew at just over $\$ 1$ billion sold at US food multi-outlet and convenience stores. This is almost double the amount sold for the second most popular, seasonal brews such as Oktoberfest and summer style beers (IRI Market Research, 2016).

\subsection{Raw materials and the brewing process}

\section{$\underline{1.2 .1 \text { Grains }}$}

The process of brewing begins with grains. Cereal grains provide the majority of sugars that are required for the production of alcohol. Barley is the most prominent grain used in the industry, though others such as wheat, rice, and corn can also be used. This 
will vary depending on the color, style, and flavor of beer being produced. Grains will provide several key attributes that define beer such as color, flavor, body, mouthfeel, and alcohol content (Jurando, 2002; Mallett, 2014).

The types of barley used for brewing can be distinguished by two basic categories; two-row and six-row. This refers to the arrangement of the kernels on the plant when viewed down the axis of the stalk. Two-row barley is more common for the production of beer, although both two- and six-row barley have their place in brewing. Two row barley contains more carbohydrates and thus fermentable material, and it will provide a fuller flavor profile than six-row barley (Kim et al., 2014). Six-row barley contains a higher enzymatic content, this higher enzymatic content increases the rate of conversion of starch to fermentable sugars. Additionally, the higher protein and solid content of six-row barley allows for greater filtration of the wort. However, with modern brewing technology, this filtration is not as important as currently used filtration devices, such as false bottoms which have been developed for this purpose. Six-row barley tends to be less expensive than two-row and it is therefore common for brewers to supplement two-row barley with six-row barley (Standridge et al., 1970).

\subsubsection{Malting}

Starches and carbohydrates are contained within the endosperm of the barley grain seed, which is encased in a tough hull. Malting is the process in which cereal grains for brewing are partially germinated. This process releases the enzymes, starches, and carbohydrates within the endosperm of the grain that are required for fermentation. The grains are steeped in water until the moisture increases by 43 to $48 \%$ by volume. At this point the grains are moved to the germination tank. During this time, the endosperm 
will continue to release hormones and produce the alpha- and beta- amylase enzymes. These enzymes are responsible for the breakdown of starch into fermentable sugars that the yeast will use to carry out fermentation. Additional enzymes are also produced in this step, these enzymes convert compounds within the endosperm into simple sugars, peptides, amino acids, and fatty acids. The enzymatic action that occurs during stage is crucial as it generates fermentable material for the yeast (Barth, 2013; Mallett, 2014).

After sufficient germination of the barley grains is achieved, the growth is halted through kilning. This is a processing step where the grains are dried and cooked. Kilning also induces the Maillard reaction which result in a variety of flavors, colors, and aromas. At this stage, the cooked grains are referred to as malt. Kilning temperature and time vary depending on the style of malt desired. Pale base malt is the most common used in the industry. A darker malt can be produced with higher temperatures and longer kilning times, while a pale malt is the result of lower temperatures and shorter kilning times. Darker malts impart more rich colors and more bitter, roasted, coffee, and burnt flavors while light malts have more of a caramel sweetness and light color. Other specialty style malts can also be produced through variation of grains, processing times, and temperatures (Jurado, 2002; Mallett, 2014).

In order to expose the endosperm beneath the husk of the barley kernel after it has been malted, dried, and kilned, it is milled. Milling is the first on site brewing step and is considered the first actual stage in the brewing process. This process allows for better extraction of the nutrients in the plant. It is important for the husk to remain as intact as possible, as later in the brewing process it is used as a natural filter. Finer particulates lead to a better extraction, but poor filtration after mashing (Barth, 2013). 


\subsubsection{Mashing}

Mashing is the process in which the milled malt is soaked in hot water which allow enzymes to break down proteins and starches. Breweries utilize a mash tun, a specialized insulated vessel with a false bottom and a controlled heat source. Temperature of the mash is brought up to around 67 to $72{ }^{\circ} \mathrm{C}$ where the enzymes released from the grains are most active. Table 1 presents the major enzymes found in wort along with their functions and active temperature and $\mathrm{pH}$ ranges (Palmer, 2006). Different enzymes present in the grains are active at specific temperature ranges, the time it takes for the mixture to reach temperature allows each of these enzymes to break down larger compounds present in their ideal temperature ranges (Palmer, 2006; Barth, 2003).

Table 1: Major enzyme groups present in grist (table adapted from Palmer, 2006).

\begin{tabular}{ccc}
\hline Enzyme & $\begin{array}{c}\text { Optimal } \\
\text { temperature } \\
\text { range }\left({ }^{\circ} \mathbf{C}\right)\end{array}$ & Functionality \\
\hline Phytase & $30-52$ & Lowers the mash pH. No longer used. \\
Debranching (var.) & $95-45$ & Solubilization of starches. \\
B-glucanase & $95-45$ & Best gum breaking rest. \\
Peptidase & $45-55$ & Produces Free Amino Nitrogen (FAN). \\
Protease & $45-55$ & Breaks up large proteins that form haze. \\
B-amylase & $55-65$ & Produces maltose. \\
A-amylase & $67-72$ & Produces a variety of sugars, including maltose. \\
\hline
\end{tabular}

Gelatinization, liquefication, and saccharification take place during the mashing process. Hydrogen bonds within the starch granules are hydrolyzed and the starch chains are separated. This is the gelatinization process and it is necessary in order for these chains to become accessible to enzymes in solution. Liquefication is the process of alphaamylase and beta-amylase breaking down starch and extracting soluble sugars into the solution. The enzyme $\alpha$-amylase is responsible for cleaving starch molecules in the 
central portion, making chains shorter. Enzymatic action of $\beta$-amylase is called saccharification and separates soluble chains of glucose from the starch molecule. This action is the conversion of starches into fermentable sugars (Barth, 2013; Mallett, 2014)

When the mashing process is complete, the concentrated sweet liquid is drained into the lauter tun. At this stage, the sweet liquid is referred to as wort. In order to extract the remaining fermentable sugars, the grains are rinsed with hot water in a process called sparging. Intact husks act as a natural filter for any particulates that could contribute haze, an undesirable characteristic in most finished beers. The hot water is drained along with the wort into the boiling kettle (Bamforth, 2009).

Wort may be diluted with water at this point or after the boil to reach the desired gravity level. Gravity of the wort refers to the amount of fermentable material for the yeast. There are several scales used; specific gravity, Plato, and Brix. Specific gravity is the ratio of the density of the wort compared to water. The Plato scale quantifies the concentration of sugars as a percentage by weight. Brix measures the strength of the aqueous sugar solution as a percentage by mass. One degree Brix is 1 gram of sucrose in 100 grams of solution. Plato and specific gravity are more commonly used in the beer industry and Brix is standard in the wine industry. However, all scales can be used interchangeably and are simply measures of the sugar content and thus fermentable material for the yeast. The most common instrument used to assess gravity in the beer industry is the glass hydrometer. Recording the initial gravity before fermentation and final gravity after fermentation allows for the determination of alcohol by volume (ABV) and the apparent attenuation, or relative efficiency of sugar consumed by the yeast (Barth, 2013) 


\section{$\underline{1.2 .4 \text { Hops }}$}

The main use of the hops plant is in the brewing industry. Hops are considered to be the "spice" of beer. The flowers of the female hops plant have been a major flavoring ingredient in beer since the 1500's. They provide bitterness, aroma, flavor, mouthfeel, stability of flavors, as well as anti-microbial attributes. Hops will impart piney, citrus, floral, herbal, estery, spicy, and fruity and several other attributes to beer. Cones of the hops plant, specifically the lupulin glands, contain the resins, essential oils, alpha- and beta-acids, as well as polyphenols that are responsible for these properties. The long history of cultivation and breeding left modern times with a vastly diverse plant, each type with unique alpha and beta acid ratios resulting in distinct flavor and aroma compounds (Barth, 2013; Hieronymus, 2012).

\subsubsection{Alpha-acids and isomerization}

Alpha-acids are the precursor to the primary bittering component in beer. These compounds are humulone, cohumulone, and adhumulone. Each varietal of the hops plant will have a unique alpha-acid content. In their natural state, alpha-acids do not contribute to bitterness and are not water soluble. Alpha acids must be isomerized in order to become water soluble and provide bitterness to the product. This isomerization reaction is detailed in Figure 1 (Jaskula et al., 2008). Hops are added at the boiling stage of brewing due to heat being required for this reaction to take place (Jaskula et al., 2008; Ting et al., 2017) 

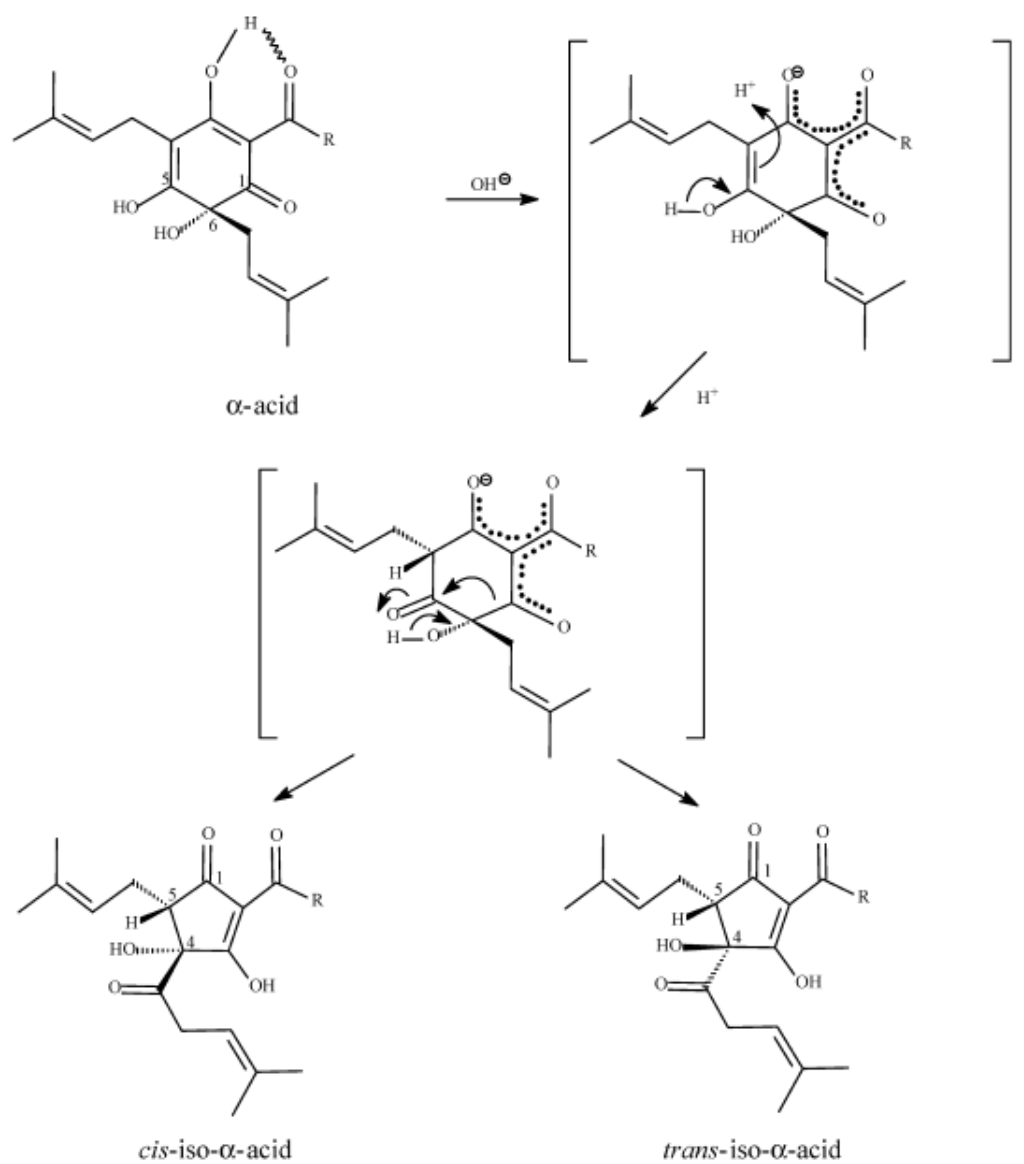

\begin{tabular}{|c|c|c|c|}
\hline $\mathbf{R}=$ & $\alpha$-acids & trans-iso- $\alpha$-acids & cis-iso- $\alpha$-acids \\
\hline $\mathrm{CH}\left(\mathrm{CH}_{3}\right)_{2}$ & cohumulone & trans-isocohumulone & cis-isocohumulone \\
\hline $\mathrm{CH}_{2} \mathrm{CH}\left(\mathrm{CH}_{3}\right)_{2}$ & humulone & trans-isohumulone & cis-isohumulone \\
\hline $\mathrm{CH}\left(\mathrm{CH}_{3}\right) \mathrm{C}_{2} \mathrm{H}_{5}$ & adhumulone & trans-isoadhumulone & cis-isoadhumulone \\
\hline
\end{tabular}

Figure 1: The mechanism of alpha-acid isomerization to iso-alpha acids (Jaskula et al., 2008).

Utilization is a measurement of isomerization efficiency and it refers to the percentage of iso-alpha acids remaining in the final product. When bittering hops are added to the wort early in the boil, utilization is increased. Typically the yield of isomerization is low, between 5 and 30\% (Barth-Haas Group, 2016). This is due to the relatively high acidity of the wort $(\mathrm{pH}=5.2)$, which inhibits the isomerization reaction. Utilization can also be affected by degradation of the alpha acids due to the heat stress of vigorous boiling. If desired bitterness levels have not been met at the end of production, 
brewers will use extracts of iso-alpha acid for precise bittering control. These extracts are manufactured using proprietary carbon dioxide extraction processes (Ting et al., 2017).

\subsubsection{International bitterness units}

International bitterness units (IBU) is a measurement of the iso-alpha acid content in finished beer. This scale is used as an approximation of perceived bitterness of the product. Measuring IBU's is useful for brewers in order to maintain consistency. The various beer styles will have specific IBU ranges. Lambics, wheat beers, and American lagers are examples of a low bitterness beer with an IBU up to 30. Porters, Pilsners, bitters, and pale ales generally are the medium bitterness levels of 30 to 50 IBUs. India Pale Ales tend to have the highest bitterness levels, from 50 IBU to upwards of 120 IBUs. (Barth, 2013; Papazian, 2013).

A common method to determine wort bitterness as IBU level is through spectrophotometry. In this method, a sample of wort is acidified with hydrochloric acid. The acidified sample is emulsified with isooctane, separated through centrifugation, and analyzed by a spectrophotometer at an absorbance of $275 \mathrm{~nm}$. Bitterness of the wort in terms of IBU is determined by using the following equation:

$$
\mathrm{IBU}=A_{275} \times 100
$$

\section{Equation 1: Bitterness measured as absorbance.}

The measurement $A_{275}$ is the absorbance of the sample at $275 \mathrm{~nm}$. With this method, IBU values are obtained relatively quickly and the brewer can ensure that desired bitterness levels have been met (American Society of Brewing Chemists, 2012). 


\subsubsection{Additional hop flavor attributes}

Additional hop aroma and flavor attributes are provided by the essential oils found in the hops. These essential oils contain hydrocarbons, oxygenated compounds, and sulfur containing compounds, all of which impart sensory attributes such as floral, citrus, spicy, and herbal amongst others. The majority (70\%) of the hydrocarbons present in hop essential oils are terpenes and sesquiterpenes. These compounds are volatile and susceptible to degradation during the boil. Later hop addition in the boil or adding hops to the fermenter (dry hopping) will impart the flavor and aroma present in terpenes and sequiterpenes (Ting et al., 2017).

Common terpenes of sensory importance found in the essential oils of hops include linalool, caryophyllene, humulene, and myrcene. Linalool is a monoterpene alcohol commonly attributed to the characteristic floral and citrus notes of the hoppy aroma present in dry hopped beers. Derivatives of the terpenes humulene and caryophyllene are responsible for the spicy and herbal characteristics of hops (Praet et al., 2016). Myrcene is a volatile compound responsible for late hop character that provides herbaceous, metallic, resinous, and spicy notes (American Society of Brewing Chemists, 2012).

In addition to terpenes and sesquiterpenes, polyphenolic compounds found in the hops also contribute to the sensory properties of beer. Polyphenolic compounds make up a small (4-6\%) portion of the hops dry weight, though they have a profound effect on the organoleptic properties of beer, namely mouthfeel, bitterness, and astringency. (Goiris et al., 2014). These compounds are classified into flavonols, flavan-3-ols, phenolic carboxylic acids, and other polyphenolic compounds such as tannins. Hop polyphenols 
improve taste stability of beer since they are naturally strong antioxidants, protecting the beer from oxidation (Almaguer et al., 2014). Additionally, the bitterness and astringency of hop polyphenols interact with and modify the bitterness perceived of iso-alpha acids. In a study conducted by McLaughlin et al. (2008) to understand the interaction of polyphenolic bitterness and bitterness from hop acids it was found that as polyphenol levels increased, a more-harsh and longer-lasting bitterness was perceived. At these higher levels of polyphenols, these beers also had medicinal and metallic characteristics (McLaughlin et al., 2008)

\section{$\underline{1.2 .5 \text { Brewer's yeast }}$}

The yeast species used for brewing is Saccharomyces cerevisiae. This singlecelled microorganism is responsible for the fermentation of sugars to carbon dioxide and alcohol. There are thousands of strains used in the brewing industry, each with unique metabolic, performance, and flocculation profiles. Yeast can be categorized into two basic types; top fermenting ale strains and bottom fermenting lager strains. Ale strains perform best at warmer temperatures $\left(12-21^{\circ} \mathrm{C}\right)$ and lager strains in cooler temperatures

$\left(4-12^{\circ} \mathrm{C}\right)$. Strains of yeast can be further differentiated on their morphology, origin, and fermentation byproducts (White et al., 2010).

Yeast is added (pitched) to the wort once it is cooled quickly after the boiling step. Pitch rate refers to the number of yeast cells added at a rate of cells per milliliter of wort per degree Plato. This ratio will vary depending on the beer style, yeast strain, and concentration of fermentable sugars in the wort. The standard pitch rate for ales is $0.75-$ 1.00 million cells per milliliter per degree Plato, while lager styles require double this amount due to low fermentation temperatures (White et al., 2010). Higher concentrations 
of fermentable sugars in the wort may also require an increased pitch rate in order to achieve more desirable fermentation outcomes (Casey et al., 1983).

The rate at which yeast is pitched is an important part of controlling yeast growth and fermentation rates. Growth rate refers to the Under-pitching can result in slower fermentations and longer lag phases due to the slower growth rate of a smaller colony. Over-pitching yeast can potentially lead to flavor development through the production of esters and yeast autolysis. However, the effects of over-pitching yeast are not as prominent as under-pitching. It is often recommended to over-pitch rather than underpitch yeast (White et al. (2010). In a study by Jones et al. (2007) it was found that increasing inoculum size can potentially aid in optimizing fermentation performance. High gravity wort $\left(22^{\circ} \mathrm{P}\right)$ was inoculated with a control rate $\left(2.2 \times 10^{7}\right.$ cell/mL $)$ and a higher rate $\left(3.08 \times 10^{7}\right.$ cell $\left./ \mathrm{mL}\right)$. More favorable fermentation outcomes were observed in samples with the higher inoculation rate such as shorter fermentation time and lower levels of diacetyl and acetaldehyde (Jones et al., 2007).

A study by Erten et al. (2007) investigated the effect of pitching rate on fermentation and flavor compounds in high gravity wort. The wort was pitched with lager yeast at a rate ranging from $1.0 \times 10^{7}$ (low) to $1.0 \times 10^{8}$ (very high) viable cells per milliliter of wort. Fermentations were carried out at $10{ }^{\circ} \mathrm{C}$ until the consumption of $80 \%$ of the sugars was reached. Viable yeast cell growth was higher in the high pitch rates compared to the low pitch rate trials, the maximum yeast cell counts were $19.9 \times 10^{7}$ cells $/ \mathrm{mL}$ for the highest pitch rate $\left(1.0 \times 10^{8}\right)$ and $4.97 \times 10^{7}$ for the lowest pitch rate $\left(1.0 \times 10^{7}\right)$. While a decrease in viability was observed for all trials, this decrease was greater in the lower pitch rates, the final viabilities were 63.3 and $72.2 \%$ for the lowest 
and highest pitch rates, respectively. In addition, the researchers monitored the formation of diacetyl and 2,3-pentanedione, two flavor compounds considered undesirable in the final product. It was observed that increasing the pitch rate by one log reduced the off flavor compounds by 50\% (Erten et al., 2007).

\subsubsection{Life cycle}

Yeast reproduce through budding, a process where the mother cell will clone itself. The daughter cell will separate and leave a bud scar on the mother's cell membrane. Cells will bud up to 20 or 30 times depending on yeast strain. Age of the cell can roughly be determined by the number of bud scars found on the cell membrane. These scars are composed primarily of chitin and can alter the fluidity of the cellular membrane, which interferes with nutrient transport as the cell ages. A healthy cell membrane will contain sufficient amounts of lipids, sterols, and proteins that provide flexibility and fluidity (Speers et al., 2015).

Flocculation is a behavior unique to yeast strains used for brewing. Towards the end of fermentation, yeast cells will adhere to one another and fall out of solution. Direction and degree of flocculation is strain dependent. Highly flocculent strains will begin to fall out of solution within 3 to 5 days, while low flocculating strains will begin to flocculate by 15 days of fermentation (Boulton et al., 2006). The mechanism for flocculation is not completely understood. Previous research has established that net surface charge, cellular age, nutrition storage, and oxygen content of the wort can all affect the yeast cells ability to flocculate (Jenkins et al., 2003).

Acidity of the environment can potentially have a direct impact on the flocculation behavior of the yeast. A study conducted by Jin et al. (2000) investigated the 
effect of environmental conditions on yeast flocculation. Flocculation of cells was measured according to the absorbance method provided by the American Society of Brewing Chemists (1996) with modifications made to the flocculation buffer. Acetate buffers of different $\mathrm{pH}$ values $(3.5-5.8)$ were used to evaluate the effect of $\mathrm{pH}$ on flocculation.. It was observed that flocculation behavior was affected by alterations of the buffer $\mathrm{pH}$, though this sensitivity was strain dependent. An increase in $\mathrm{pH}$ induced greater flocculation in both strains studied. It was concluded that this was likely due to the external $\mathrm{pH}$ causing alteration of the ionization and surface charge of proteins located on the cell wall (Jin et al., 2000).

\subsubsection{Metabolism and growth}

Yeast cells utilize sugars in a specific order. This is due to the relative difficulty of transporting the different sugars across the cellular membrane. Glucose is the most easily transported sugar and transporting across the cell membrane does not require the cell to expend energy. Maltose is the most abundant sugar present in wort and is the second in order that yeast intake (Boulton et al., 2006). The composition of wort in terms

of sugars and nutrients present directly affect yeast metabolism and therefore the speed of attenuation (Taidi et al., 2003).

The yeast cells will first undergo aerobic metabolism, or respiration. Cells will intake oxygen and generate the greatest amount of energy from sugars through this pathway. This is the preferred method for yeast cells to metabolize nutrients and encourages cellular colony growth. For this reason, aeration of the wort is crucial for the initial colony growth phase (White et al., 2010). Sugars in the wort are converted to pyruvate and then acetyl carboxylase. At this stage the cells generate sterols and 
unsaturated fatty acids that are vital to cellular membrane fluidity. Acetyl carboxylase is also used in the Krebs cycle, a series of reactions that generate stored energy in the form of adenosine triphosphate (ATP) (Boulton et al., 2006).

The lag phase refers to the time it takes for sufficient yeast colony growth to occur and oxygen in solution to deplete. This is essentially the time it takes for yeast to complete respiration. No activity in terms of ethanol production is observed during this time, though the number of cells in solution increases significantly. The time it takes for this lag phase to complete is strain and style dependent, though on average lag phase is finished in 12 to 24 hours (White et al., 2010).

\section{$\underline{1.2 .5 .3 \text { Fermentation }}$}

The brewing process requires the anaerobic metabolism of fermentation. This pathway does not provide as much energy in the form of ATP as aerobic respiration, though it allows yeast to survive in a low to no oxygen environment. Fermentation occurs over several steps, though simplified it occurs over the conversion of glucose to pyruvate, followed by pyruvate to ethanol, carbon dioxide, and ATP. Ethanol is toxic to yeast and tolerance of ethanol is strain dependent. When either the tolerance level is reached or sugars in solution are sufficiently depleted, the cells begin to flocculate or die (Lentini et al., 2003).

Once primary fermentation is complete, the nearly ready "green beer" may be filtered and transferred to the secondary fermenter depending on recipe. At this point dry hops, fruits, and other flavor additions may be added. This is considered the stationary phase for the yeast where remaining cells reabsorb certain flavor components that cause off notes in beer such as diacetyl and acetaldehyde. Diacetyl is the most common off 
flavor, providing a buttery note and slick mouthfeel. High concentrations of diacetyl indicate that fermentation is not finished, while low concentrations indicate fermentation completion (Pickerell et al., 1991).

\section{$\underline{1.3 \text { Yeast assessments }}$}

\subsubsection{Viability}

The relative fitness of a yeast culture for fermentation can be determined by its viability (Layfield et al., 2015). Yeast viability is expressed as the percentage of live cells out of total cells. Most breweries will discard yeast if the viability falls below a predetermined value. A common viability threshold set is between $85-90 \%$ viability (Boulton et al., 2006). Additionally, compounds indicative of cellular stress and underperformance such as diacetyl are detected at the end of fermentation at these lower viability values (Powell et al., 2007).

Typically a rapid cell count is obtained through staining methods. A sample of yeast slurry is treated with methylene blue and enumerated on a hemocytometer counting chamber under a microscope. Dead and non-viable cells will appear medium to dark blue (American Society of Brewing Chemists, 2005). The methylene blue staining method is common in the brewery setting due to the low cost and fast results. However, results can be subjective due to operator variability. Other methods such as flow cytometry can be used to achieve higher accuracy at an increased cost (Boyd et al., 2003). Slide cultures can also be utilized for viability and vitality assessment, though require 12 to 14 hour incubation time and therefore not practical in the brewery setting (Layfield et al., 2015). 


\section{3 .2 Vitality}

Vitality refers to the overall activity and physiological condition of the population. The key difference between vitality and viability is that cells may be alive, but not active or "vital" enough for a healthy fermentation. Both viability and vitality are often used as assessments to describe the fitness of a yeast culture for fermentation. A population's vitality can be measured through metabolic activity, oxygen uptake slurry pH, plating, and wort acidification. (Boulton et al., 2006; Layfield et al., 2015). Increase in cellular age as well as cellular stress cause the vitality of yeast populations to decrease and thus a drop in relative performance for fermentation is observed (Powell et al., 2003).

\subsubsection{Cellular stress}

Exposure to certain conditions induces a stress response within the yeast cell and could potentially lead to cellular death. These stress responses can be indicative of underperformance and poor yeast health, both of which can lead to undesirable fermentation outcomes and thus an inferior final product. For these reasons it is important for brewers to monitor certain markers of yeast health in order to ensure quality in the finished beer (Boulton et al., 2006). There are several markers that can be analyzed including apparent attenuation, viability, and vitality as previously discussed. These markers will show a decrease when cells are exposed to stress. Slurry $\mathrm{pH}$, production of cell wall trehalose, protease, long chain fatty acids, and sterols are also used to monitor cellular stress (Martin et al., 2003).

While it is a desired product of fermentation for the brewer, ethanol is toxic to yeast. The accumulation and exposure to ethanol at higher concentrations during the fermentation process negatively impacts the physiological status of the yeast cells 
(Kobayashi et al., 2007). In one study, overall vitality, trehalose and protease release, cell wall and membrane structure, and cell membrane fluidity were monitored of yeast exposed to ethanol concentrations of either 5 or $10 \%(\mathrm{v} / \mathrm{v})$. It was found that in response to the higher ethanol content $(10 \% \mathrm{v} / \mathrm{v})$, yeast would actively seek out oxygen in order to produce more cellular membrane unsaturated fatty acids. This process results in the modification of the fluidity of the cell membrane to ensure cellular integrity in response to the external stress. This means that more energy is being spent on survival and adaptation than the conversion of sugars to ethanol, which could potentially slow the process of fermentation. Additionally it was found that cell wall trehalose increased with greater exposure to ethanol (Lentini et al., 2003). Cell wall trehalose has been shown to be a powerful protectant against osmotic, thermo-, and chemical stress (Wiemken, 1990).

A study by Zhuang et al. (2017) investigated the impact of extracellular osmotic pressure on yeast populations during brewing fermentations. Standard, high gravity, and very high gravity fermentations were carried out to determine the effects on yeast at the physiological and molecular level. Gravity levels were set at 13,18 , and $24^{\circ}$ Plato, for the standard, high gravity, and very high gravity fermentations, respectively. Osmotic pressure was determined with a micro-osmometer and expressed as osmolality, the number of milliosmoles of osmotically active particles per kilogram of solvent. Osmolality was observed to increase for all gravity levels; from 700 to 1,500, from 800 to 1,800 , and 1,100 to $2,500 \mathrm{mOsm} / \mathrm{kg}$ for the 13,18 , and $24^{\circ}$ Plato fermentations, respectively. Due to the concentrations of each component analyzed for osmolality, it was concluded that ethanol was the major contributor to the extracellular osmotic pressure observed during fermentation (Zhuang et al., 2017). 
Additionally in this same study by Zhuang et al. (2017) an osmotic challenge was conducted using by growing yeast in various concentrations of sorbitol solutions $(0,10$, $20,30,40$, and $50 \% \mathrm{w} / \mathrm{v}$ ) to represent the range of external osmotic pressure due to ethanol observed during fermentation. Yeast viability, vitality, intracellular trehalose and glycerol content, as well as membrane fluidity were also measured. It was found that as osmotic pressure increased along this range, yeast viability, vitality, and cell membrane fluidity decreased. However, cell wall trehalose and glycerol production increase, indicating a stress response had been induced. It is possible for this response to osmotic stress to have a direct impact on yeast performance and product quality due to the suppression of other carbon-based metabolite production by the presence of trehalose (Thevelein et al., 1995).

In addition to high ethanol content, the presence of oxygen could also lead to cellular stress. Occurrences of oxidative stress happen when yeast cells are in contact with oxygen or reactive oxidative species (ROS). In the brewery setting, this may happen during handling procedures, pitching, propagation or storage of the yeast slurry (Boulton et al., 2006). Tolerance to oxidative stress is strain dependent. Lager strains have been shown to be more tolerant of oxidative stress than ale strains, though the reason is unknown. When exposed to an increase in ROS, cellular damage is observed in DNA as well as membrane lipids and proteins which results in poor membrane function, fluidity, and permeability Cellular damage to DNA incurred from oxidative stress which lead to changes and mutations that make yeast undesirable for beer production (Martin et al., 2003). 
Changes in $\mathrm{pH}$ of the wort and yeast slurry are observed as fermentation continues. Monitoring these changes provides insight of the viability and vitality of the cells (Mochaba et al., 1998). Cellular stress incurred from prolonged storage can cause an increase in slurry $\mathrm{pH}$, indicating autolysis, or self-digestion, has occurred. Autolysis releases diacetyl, fusel alcohols, and acetate which cause undesired sensorial off-notes in the final product. A downshift in wort $\mathrm{pH}$ is normal up to 1.5 to 2 , though extreme changes in wort or slurry $\mathrm{pH}$ can be indicative of cellular stress (Coote et al., 1976). Extreme changes in $\mathrm{pH}$ are associated with genetic and physiological changes in the yeast that make it unfit for fermentation (Layfield et.al, 2015).

Mochaba et al., (1998) investigated a series of procedures to overcome common issues associated with yeast quality measurement. It was indicated that slurry $\mathrm{pH}$ has a direct relationship with both autolysis and protease activity. The $\mathrm{pH}$ of three yeast storage vessels were observed over time. A significant increase in $\mathrm{pH}$ over time was observed over the 40 hour period (4.8-5.5). This increase in $\mathrm{pH}$ was accompanied with the release of free amino nitrogen (FAN). Higher concentrations of FAN lead to increased levels of compounds that are considered defects in the final product such as diacetyl, acetate, and fusel alcohols. It was noted that pitching with higher $\mathrm{pH}$ yeast slurry leads to insufficient $\mathrm{pH}$ downshift over the fermentation process, further negatively affecting the organoleptic properties of the final product (Mochaba et al., 1998).

\subsection{Specialized brewing techniques}

There are several techniques utilized at the brewery scale to increase production efficiency, consistency, and keep up with consumer demands and market trends. Though beneficial to the brewer in saving time, space and resources, these conditions have been 
shown to induce stress responses in the yeast, decreasing viability and vitality. These decreases lead to undesirable fermentation outcomes and poor quality final product. However if yeast health is closely monitored, these techniques can be used successfully without severe negative outcomes either alone or in combination. These techniques include high gravity brewing and repitching. Additionally, high IBU fermentations are more prevalent as the popularity of the IPA style increases.

\subsubsection{High gravity brewing}

Typically the starting gravity of the wort is 10 to $14{ }^{\circ}$ Plato (1.040-1.057 Specific Gravity). High gravity brewing is the fermentation of wort $16^{\circ}$ Plato and above. The increase in fermentable material for the yeast results in a beer with $7 \% \mathrm{ABV}$ or higher. Brewing at these levels increases production volume by decreasing the amount of space and time required for several different beers. The final product may be bottled as is, or diluted with deoxygenated sterile water to reach the desired ABV level (Stewart, 2014). Previous research indicates that in trained sensory panels, consumers were unable to discern the difference between a beer that had been brewed at a lower gravity level and high gravity beer that had been diluted (Silva et al., 2008). However, it has been shown that increased gravity levels can negatively impact yeast health and fitness for fermentation (Zhuang et al., 2017).

Losses in both viability and performance in both the immediate 24 hours following pitching and over the course of high gravity fermentations have been observed. For this reason higher gravity brewing often requires an increase in pitch rate to overcome the losses in viability. This loss in viability is due to the dramatic increase in osmotic pressure from the high sugar load. Response to this stress also include reduced 
attenuation rates and stuck fermentations that could negatively impact the flavor of the final product (Casey et al., 1983) Additional osmotic stress occurs as the fermentation continues and more ethanol is produced. Yeast respond and adapt to this stress through the production of cell wall trehalose (Lentini et al., 2003). Previous research has indicated that higher gravity fermentations result in yeast slurries with lower viability at the end of fermentation (Stewart 2014).

The vacuole is considered to be an indicator of the physiological state of the yeast cell. Shifts in vacuolar size can be observed over the course of fermentation to adapt to external factors. However extreme changes in vacuolar size are associated with cellular stress, as observed by Meaden et al. (1999). The internalization of vital lipophilic dye (FM 4-64) as well as vacuolar morphology in the presence of 6\% (v/v) ethanol were monitored at $0,5,15,30$, and 60 intervals. It was found that this concentration of ethanol led to an accumulation of dye in membrane components involved with intracellular transport. As time increased it was noted that this shifted and the staining occurred only at vacuolar membrane, indicating that the vacuole is the organelle responsible for adjustments needed in order to overcome environmental stress caused by the ethanol. It was also observed that the morphology of the yeast vacuole significantly changed from a segregated structure to a large, swollen organelle. Similar observations were made when yeast cells were subjugated to heat shock (Meaden et al., 1999).

In a scanning electron microscope study, Pratt et al., (2007) compared the morphology of yeast in conventional gravity wort (12 ${ }^{\circ}$ Plato) and high gravity wort (20 ${ }^{\circ}$ Plato). It was noted that more significant changes in vacuolar size occurred with the high gravity wort, which was indicative of environmental stress induced on the cell. For 
both the ale and lager strains of yeast vacuole size greatly decreased following the first 6 hours of high gravity fermentations when compared to the low gravity fermentations. It was concluded that this was a result of the increase in osmotic pressure caused by the initial sugar concentration. Following the stationary growth phase, an increase in vacuole size was observed for all samples. This was more significant for the high gravity samples, which also exhibited undesirable fragmentation of the vacuole. It was noted that the swelling and fragmentation of the vacuoles in the high gravity samples was due to limited environmental nutrients and increased exposure to ethanol (Pratt et al., 2007).

Towards the end of high gravity fermentations, complications arise due to the increased ethanol content. Lentini et al. (2003) investigated the impact of ethanol stress on yeast physiology. Several parameters of yeast health were measured at different ethanol content (5 and 10\% v/v), these parameters included membrane lipid composition. A major increase in unsaturated fatty acids was observed in the high (10\% v/v) ethanol samples, indicating a stress response to ensure integrity of the cell membrane when presented with environmental stress. Yeast actively seek out oxygen as it is required for the production of these unsaturated fatty acids. However, at this point in the fermentation process oxygen in solution has already been depleted. This results in the inability of yeast to adapt to their environment and cellular damage or death. The results of the membrane composition were accompanied with lower viabilities in the high ethanol (10\% v/v) samples at the end of the storage period when compared to the low ethanol $(5 \% \mathrm{v} / \mathrm{v})$ samples (Lentini et al., 2003). 


\subsubsection{Repitching}

Often breweries harvest a yeast slurry from a previous fermentation to pitch in fresh wort through a process called repitching. Reuse of yeast in this way can be performed for 8-15 successive fermentations depending on strain and brewery operating procedures and policies. This technique saves time and resources as propagation of a new yeast slurry is not required (Boulton et al., 2006). However, repitching induces a repeated stress injury cycle on the yeast that corresponds to cellular responses that negatively impact beer quality. A comprehensive study by Martin et al. (2003) identified yeast response mechanisms to cellular damage that occurs during brewery handling, including a portion on serial repitching of yeast over eight generations. Trehalose content of the cells had a positive correlation with generation number, while cellular glycogen content decreased. In tandem these changes over generations are representative of cellular stress and underperformance. It was suggested for yeast to not be repitched excessively (15-20 times) in order to avoid genetic drift that could lead to inconsistent fermentation outcomes and undesirable flavor development (Martin et al., 2003).

Jenkins et al. (2003) demonstrated the impact of serial repitching on brewing yeast quality through several common assays of biomarkers. A production lager strain was used for this experiment and obtained by cropping from the fermentation vessel and storage tanks. Yeast quality parameters, which included trehalose content and frequency of petite mutation, were monitored over seven repitching cycles for a total of eight generations. The overall condition and fitness for fermentation declined as generation number increased. A strong correlation between intracellular trehalose content and generation number was observed. This increase in trehalose is symptomatic of cellular 
stress. Frequency of petite mutation was also analyzed over the eight generations according to the TTC method. The final generation presented significantly more occurrences of petite mutation than the initial generation. It was concluded that the accumulated modifications to physiology, mutations, and cellular damage was primarily responsible for the deterioration in yeast quality (Jenkins et al., 2003)

In an experiment conducted by Powell et al. (2007) it was suggested that suitability for serial repitching is related to the genetic stability of the yeast. An ale strain from Bridgeport Brewing Company was chosen for full scale (150 barrel) continuous fermentations in $13.5^{\circ}$ Plato wort for 135 generations. Both colony morphology and assessment of genetic variation through RAPD-PCR were monitored. The particular sequences chosen (Ty and $\delta$ ) were identified as valuable in the detection of significant genetic changes (Wightman et al., 1996). Powell et al. (2007) observed that while slight morphological differences occurred over the 135 generations, the genetic fingerprints analyzed did not differ significantly for this particular strain of ale yeast. It was concluded that the extremely infrequent repropagation of yeast by this brewery as well as the lack of selective environmental factors had produced a yeast that has great capacity for serial repitching. However, it was noted that certain strains are more susceptible to genetic drift than others and this genetic stability is important to take into account in selecting yeast for production (Powell et al., 2007).

In addition to the repeated stress-injury cycle endured by repitching, increased yeast handling procedures exposes yeast to potential contamination of spoilage microbes. Increasing the time that yeast is handled greatly increases the risk of contamination of spoilage microorganisms. To overcome the risk of introducing unwanted 
microorganisms, occasionally the slurry is washed with phosphoric acid in between repitching (Martin et al., 2003). Cunningham et al. (2000) assessed the quality acid washed yeast compared to yeast washed with a sterile water control in standard $\left(12^{\circ}\right.$ Plato) and high (20 Plato) gravity successive fermentations for five generations. No significant difference was observed in fermentation performance between the acid washed and the control yeast when the cultures were in good physiological condition. It was noted that if acid washing is employed, oxygenation of the yeast slurry is vital in order to stimulate growth and improve the efficiency of fermentations. Additionally, it was reported that the oxygenation of the slurry improved yeast resistance to damage from both acid washing and high gravity fermentations. (Cunningham et al., 2000)

\subsubsection{Combining repitching and high gravity fermentations}

Utilizing high gravity fermentation and repitching in tandem is often done to maximize plant efficiency. Independently these techniques induce stress responses within the cell. When combined, the impact of this stress on yeast health is amplified (Stewart, 2014). Repeated exposure to increased osmotic pressure from the initial high sugar content as well as the final high ethanol level is damaging to yeast physiology. This damage is more evident as generation number increases (Jenkins et al., 2003).

Additionally, cellular damage in stress from these exposures has been shown in previous studies to encourage mutations that can lead to unpredictable and undesirable fermentation outcomes (Jenkins et al., 2009). In a high gravity continuous fermentation experiment conducted by Pires et al. (2014) yeast performance, viability, and production of volatiles was monitored over 54 days. Seven continuous fermentations were completed with an average high gravity of $15.24^{\circ}$ Plato. Viability of the yeast biomass decreased as 
generation number increased. Accumulation of diacetyl over the seven fermentations occurred as well, indicating cellular stress and underperformance due to lack of reuptake of this compound (Pires et al., 2014).

The laboratory of Jones et al. (2007) sought to optimize the process of very high $\left(22^{\circ}\right.$ Plato) gravity beer production in order to save costs and improve efficiency. The parameters modified to combat the negative effects of repitching and high gravity fermentations were fermentation temperature, pitch rate, and oxygen supply. It was noted that of these parameters, oxygen levels were particularly important due to its role in yeast growth and metabolism. Oxygenation of the wort occurred either immediately or 12 hours following inoculation to reach target dissolved oxygen (DO) levels of 22 and 25 ppm, respectively. It was concluded that the supplementation of oxygen at 12 hours following inoculation significantly improved the outcome of the very high gravity successive fermentations. The oxygenation strategies outlined for process optimization could potentially be applied in the industrial brewing setting, they may not however be practical or ideal for a smaller craft brewery (Jones et al., 2007).

\subsubsection{High IBU}

The craft IPA is currently the most popular style on the market. This style is extremely bitter with 50 IBU or higher, requiring an increased amount of iso-alpha acids derived from hops. It is common for this style to also have a high ABV, greater than $6 \%$. These traits are effective inhibitors of unwanted microbial growth of spoilage microorganisms (Srinivaan et al., 2004). However, the impact of these traits on brewer's yeast have not been extensively researched. 
In a study of hops acids content on spent yeast, it was observed that when harvested post-fermentation, the yeast contained significantly more iso-alpha acids than the corresponding beer product. This was 7- to 10-fold greater for both light and dark ales (Bryant et al., 2015). While this study focused on the potential of diverting this waste product to a nutritional supplement, there are implications as to if this adherence to the yeast cells affects function and fermentation performance. In an observational study conducted by a brewer, yeast harvested post fermentation exhibited a pattern of lower viability as IBU level increased. The gravity of the fermentations was not disclosed, though all other factors remained similar (Edgerton, 2005).

A tolerance study of iso-alpha acids in yeast noted that the majority of cellular sequestration of hops acids occurs in the vacuole and cell wall. The retention of hops acids altered the composition and charge of the cell wall, which hindered flocculation capacity and inhibited nutrient transport. Additionally, hops acids in solution chelated with zinc and significantly reduced the bioavailability. Zinc is an important cofactor for many enzymes and a reduction of bioavailability of zinc is associated with reduced growth rates. It was concluded that these results had serious implications for brewing yeast strains, especially for repitching (Hazelwood et al., 2009).

\section{$\underline{1.5 \text { Conclusion }}$}

The craft beer industry continues to experience exponential growth in recent years. It is important for breweries to increase production efficiency in order to keep up with consumer demands and market trends. A positive physiological status of the yeast is vital to manufacturing high quality and consistent beer. High gravity brewing and repitching, both alone and in combination, have been shown to be advantageous to the brewer by 
increasing volume of production. However, previous research indicates these techniques have negative implications on yeast health. Careful monitoring of certain biomarkers and performance factors can allow breweries to successfully use these techniques a number of times.

Popularity of the craft IPA style presents additional extrinsic factors that may have serious implications on yeast health and thus brewery operations. These beers tend to be fermented at higher gravities to reach the increased alcohol content, which previous research has shown to negatively impact yeast health and performance over time. Additionally, these beers tend to have higher IBU values. There is little research examining the effects of increased bitterness values on yeast health, though the literature available implies this increase has negative implications for yeast health. The impact of combining high gravity and high IBU fermentations on yeast health has not been previously documented. These effects must be evaluated as well as their impact on repitching cycles in order to better understand how these affect outcomes of the final product. 


\section{THE EFFECT OF ALCOHOL AND BITTERNESS LEVELS ON BREWING YEAST VIABILITY}

\section{$\underline{2.1 \text { Introduction }}$}

Current trends in the United States craft beer market show that high alcohol by volume (ABV) and high bitterness styles are the most widely consumed. Within the US food multi-outlet and convenience store sector, over \$1 billion USD in sales were attributed to the craft India Pale Ale (IPA). This was double the amount of the second best-selling styles which included seasonal brews such as summer, Oktoberfest, and other high ABV beers (IRI Market Research, 2016).

High ABV styles are achieved through high gravity fermentation. This method of brewing allows for the production of highly alcoholic beers with an ABV of 5\% and above. Typically this method requires the initial gravity of the wort to be $16^{\circ}$ Plato and above. In addition to allowing for the production of popular high ABV styles, high gravity brewing can be utilized to increase brewery efficiency. The resulting high alcohol beer can also be diluted to attain the desired ABV level in order to produce several different beers. This method increases efficiency by reducing the time and space required for production. Though this is advantageous for the brewery in creating widely consumed beers and increasing efficiency, high initial gravities can induce a stress response in the yeast due to the increased osmotic pressure from the high sugar content (Pratt et al., 2007; Stewart, 2014; Zhuang et al., 2017).

In these strenuous conditions it has been observed that yeast cells will modify the composition of the cell wall in order to adjust to the environment and survive. This can 
be indicated by an increased production of unsaturated fatty acids and cell wall trehalose. Both of these compounds are key components in regulating the stability and fluidity of the cellular membrane. This membrane fluidity is vital as it regulates the intake and output of nutrients and metabolites (Martin et al., 2003).

Organoleptic properties of the final product can be significantly affected by stress response of the cells. Diacetyl is a commonly observed undesirable flavor component in beer. Typically increased levels of diacetyl will be present when yeast are exposed to high stress conditions. Diacetyl provides an undesirable buttery taste and slick mouthfeel. Incomplete or slowed fermentations have high levels of this compound. Reduced attenuation rates can be a consequence of stress caused by high gravity brewing (Pickerell et al., 1991). Previous studies have also found that higher levels of protease have been observed as a response to stress conditions. This enzyme aids in the breakdown of proteins in the wort in order for the cells to adapt to the high osmotic stress from the environment. However from a brewer's perspective, increased levels of protease are associated with inferior product attributes such as poor head retention, body, and mouthfeel of the beer (Lentini et al., 2003).

In addition to typically having high ABV levels, the popular IPA style is characterized by increased levels of perceived bitterness. This bitterness is attributed to isomerized alpha acids (iso-apha acids) that are derived from the hops plant during the boiling step of the brewing process (Hieronymus, 2012). The bitterness levels of the beer can be quantified by measuring the iso-alpha acid content and expressed as International Bitterness Units (IBU). This scale provides an approximation of perceived bitterness and can be used to assess quality and consistency. Additionally, the IBU scale can be used to 
classify certain styles of beer as these have specific ranges for IBU value. Typically IBU values of 30 and below are considered low bitterness styles while beers with an IBU value of 50 or higher are considered very bitter (Barth, 2013; Papazian, 2013).

The inclusion of hops to beer provides bitterness, flavor, aroma, as well as protection of the final product from spoilage through inhibition of bacterial growth. Previous research has shown that lactic acid bacteria, a common spoilage microorganism in the brewing industry, is effectively inhibited by iso-alpha acids (Sakamoto et al., 2003). However, the impact of IBU levels on yeast health and fermentation performance has not yet been fully investigated. It has been suggested in previous research by Ederton (2013) and Hazelwood et al., (2009) that higher IBU levels have negative implications on yeast health and fermentation outcomes. In an observational study conducted by Ederton (2013), it was noted that yeast post fermentation exhibited a pattern of lower viability when harvested from higher IBU beers (Ederton, 2013). A tolerance study by Hazelwood et al. (2009) concluded that the addition of iso-alpha acids reduced the bioavailability of zinc. Zinc is an important cofactor for several enzymes important in yeast metabolism. The integrity of the cell membrane and vacuole were also compromised as it was found that these organelles retained compounds from the hops. This retention partially inhibited intercellular transport. It was concluded that these factors could present serious consequences for brewing yeast strains, especially those used for repitching (Hazelwood et al., 2009).

Once fermentation is complete it is common for breweries to harvest and reuse yeast to inoculate a fresh batch of wort in a process called repitching. This is often repeated for 8 to 15 times depending on brewery protocols and yeast health. Repitching 
allows for the conservation of time and resources as propagation of a new culture is not needed. However, the accumulation of stress on the cells can cause issues with beer quality (Powell et al., 2007). It has been observed in previous research that repeated exposure to the stress cycle of repitching leads to poor flavor development, extended lag phases, poor attenuation rates, and poor flocculation rates. Successive repitching has also been shown to cause decreased viability and vitality measured in between fermentation cycles as generation number increases (Jenkins et al., 2003).

High gravity brewing and repitching are often used in tandem to maximize plant efficiency. Brewers can successfully employ both of these techniques for a number of times before quality is affected, though greater care must be taken in order to maintain yeast health. Previous research indicates that the combination of these techniques have cumulative effect on yeast viability, vitality, and performance due to the repeated stress injury cycle of exposure to both the high initial sugar concentration of the wort and final high alcohol level of the finished fermentation (Martin et al., 2003).

With the popularity of the IPA and high ABV beers, it is important and beneficial for the brewer to also understand the impact that other characteristics of these styles have on yeast health and performance. While high gravity brewing and repitching have been extensively researched, no study has investigated the impact that increased iso-alpha acids have on brewing yeast viability and performance, let alone the compound effects of all of these commonly employed techniques. The objectives of the present study were to observe the effects that increased IBU levels and high gravity brewing had on yeast health and performance over several repitching cycles. 


\subsection{Materials and methods}

\subsubsection{Yeast propagation}

Yeast culture was obtained from White Labs (White Labs Pure Yeast \& Fermentation; San Diego, CA). California Ale Yeast WLP 001 PurePitch was stored at $4^{\circ} \mathrm{C}$ until starter culture was prepared according to the standard method described by White et al. (2013). Dry malt extract (DME) and reverse osmosis filtered water (Kirkland Signature; Seattle, WA) were combined in a 1-liter glass bottle to reach a target gravity of $10{ }^{\circ}$ Plato. Bottles were placed in the autoclave to sterilize at $121^{\circ} \mathrm{C}$ for 15 minutes. After cooling to ambient temperature, yeast was added to the mixture and the bottle was fixed with an airlock to allow for carbon dioxide release. Yeast starter cultures were placed in an incubator at the optimal fermentation temperature $\left(22^{\circ} \mathrm{C}\right)$ for the strain selected. Cultures were grown for 24 to 48 hours prior to inoculation.

\subsubsection{Wort preparation}

\subsubsection{Dilution}

Approximately 3 to 5 gallons of wort was collected from local breweries and stored at $4^{\circ} \mathrm{C}$ until needed. The wort arrived at an average concentration of $20 \pm 1.5^{\circ}$ Plato. Reverse osmosis filtered water (Kirkland Signature; Seattle, WA) was used to dilute the stock wort to prepare 2.8 liters of each of the desired levels to represent low gravity (10 ${ }^{\circ}$ Plato $)$, medium gravity $\left(14^{\circ}\right.$ Plato $)$, and high gravity $\left(18^{\circ}\right.$ Plato $)$ fermentations. The volumes of each gravity level were divided evenly between four 1-liter glass bottles and autoclaved at $121^{\circ} \mathrm{C}$ for 15 minutes to sterilize. Thrub was filtered out of the wort with coffee filters and a funnel into a graduated cylinder. All equipment was sanitized with either $70 \%$ ethanol or a 300 ppm phosphoric acid dodecylbenzenesulfuric acid blend 
(StarSan, Five Star Chemicals \& Supply, Inc.; Commerce City, CO). Sterilized 1-liter glass bottles were filled with $725 \mathrm{~mL}$ of the filtered wort. For each gravity level, three samples were prepared. Prior to inoculation, caps were fastened tightly and each bottle was shaken by hand for 60 seconds to aerate.

For analysis $125 \mathrm{~mL}$ of wort was extracted. Before and after fermentation specific gravity, $\mathrm{pH}$, and temperature were recorded. Specific gravity was measured with a hydrometer. Reading were adjusted for temperature corrections. Apparent attenuation was calculated using the measured starting gravity (SG) and final gravity (FG) in the following equation (Papazian, 2013):

$$
\text { Apparent attenuation }=\frac{[(\mathrm{SG})-(\mathrm{FG})]}{\mathrm{SG}}
$$

\section{Equation 2: Apparent attenuation estimation.}

Using final gravity and starting gravity measurements alcohol by volume (ABV) was also calculated using the following equation (Papazian, 2013):

$$
\mathrm{ABV}=\left[\frac{76.08 \times(\mathrm{SG}-\mathrm{FG})}{1.775-\mathrm{SG}}\right] \times\left[\frac{\mathrm{FG}}{0.794}\right]
$$

\section{Equation 3: Alcohol by volume estimation.}

\subsubsection{Iso-alpha acid addition}

Isohop, a 30\% (w/w) iso-alpha acid concentrate was provided by Barth-Haas Group (Yakima, WA). The IBU levels chosen were representative of low (25 IBU), medium (50 IBU), and high (75 IBU) bitterness styles. The extract was added to the filtered wort prior to aeration (Table 2). Volume of extract to add to reach the desired 
IBU levels was calculated using the equation provided specification sheet assuming $80 \%$ utilization:

Amount of Isohop (30\% IAA) in $\mu \mathrm{L}$ per $\mathrm{mL}$ wort $=\mathrm{IBU} \times 3.9 \times 10^{-3} \mu \mathrm{L} / \mathrm{mL}$

Equation 4: Volume of Isohop for desired IBU level

Table 2: Volume of Isohop added for each of the IBU levels.

\begin{tabular}{cc}
\hline Concentration (IBU) & Volume of Isohop $(\boldsymbol{\mu L})$ \\
\hline 25 & 70.7 \\
50 & 141.4 \\
75 & 212.1 \\
\hline
\end{tabular}

Verification of IBU levels was completed using the international method of analysis provided by the American Society of Brewing Chemists (2012). Precisely 5.0 $\mathrm{mL}$ of wort and $5.0 \mathrm{~mL}$ of $18 \mathrm{M} \Omega$ reagent water were added to a $50 \mathrm{~mL}$ centrifuge tube. The mixture was acidified with $1 \mathrm{~mL}$ of $3 \mathrm{~N} \mathrm{HCl}$, followed by $20 \mathrm{~mL}$ of isooctane for extraction of the iso-alpha acids. The tubes were securely closed and shaken by hand to emulsify for 15 minutes. Emulsified samples were then placed in the centrifuge at a minimum speed of $1,164 \times \mathrm{g}(\mathrm{RCF})$. Once the isooctane layer had separated, this layer was transferred to a $1 \mathrm{~cm}$ quartz cuvette and analyzed on a spectrophotometer at $275 \mathrm{~nm}$ wavelength. The IBU of the wort was calculated using the following equation from the method of analysis provided by the American Society of Brewing Chemists (2012) where $\mathrm{A}_{275}$ is equal to the absorbance of the sample at $275 \mathrm{~nm}$ :

$$
\mathrm{IBU}=\mathrm{A}_{275} \times 100
$$

\section{Equation 5: IBU calculation from absorbance.}




\subsubsection{Fermentation conditions}

Target volume for fermentation was $600 \mathrm{~mL}$. The first generation of samples were inoculated with the starter culture at a $7.5 \times 10^{-5}$ live cells $\mathrm{mL}^{-1}{ }^{\circ} \mathrm{Plato}^{-1}$, a standard for ales according to White et al. (2010). Fermentations were carried out for 5 days at $22^{\circ} \mathrm{C}$. All 1 liter bottles were capped with an airlock to allow for release of $\mathrm{CO}_{2}$.

\section{$\underline{2.2 .4 \text { Yeast viability determination }}$}

Cell density (cells/mL) and viability (live cells/total cells) was determined using the international method of yeast cell staining provided by the American Society of Brewing Chemists (2005). Equal parts aqueous methylene blue solution (0.01 g/100 mL) and diluted yeast slurry sample were combined. Sample was allowed 1-5 minutes of contact time with the stain before enumeration on a hemocytometer. Dead and non-viable cells appeared medium to dark blue and viable living cells appeared clear. Yeast viability could be calculated through the enumeration of dead and total cells. Cell counts were performed after fermentation and prior to inoculation into the next generation of samples.

\section{$\underline{2.2 .5 \text { Data analysis }}$}

All gravity levels at each generation were done in triplicate. Data points are expressed as the mean \pm standard deviation. Analysis of variance (ANOVA) and Tukey's test were performed to assess significant differences between samples at each gravity level and between samples at different generations. Minitab software was used for the analysis (version 18; NIST; Gaithersburg, MD). 


\subsection{RESULTS AND DISCUSSION}

\section{$\underline{\text { 2.3.1 High gravity successive fermentations }}$}

The goal of this study was to evaluate the impact that a high initial gravity had on yeast health and performance, as well as to develop methodology for a benchtop repitching procedure. Previous research has been conducted on the effects of initial high gravity and repitching. It has been found that higher starting gravities resulted in lower viability, stalled fermentations, undesirable flavor characteristics, and cellular damage (Lentini et al., 2003, Pratt et al., 2007, Martin et al., 2003). An additional goal for this initial study was to compare results to what has been reported in the literature.

\subsubsection{Effect of high gravity successive fermentations on apparent attenuation}

While apparent attenuation is not the standard benchmark of yeast health, when paired with viability it can be a powerful tool in assessing fermentation progress and performance (White et al., 2010). This strain of California Ale Yeast (WLP 001) has potential to reach up to $73-80 \%$. However, this will also vary depending on the quality and types of fermentable material available in the wort (Lei et al., 2016).

Apparent attenuation was assessed at the end of the five day fermentation period and means are reported (Figure 2) for each gravity level. Results of the low gravity $\left(10{ }^{\circ} \mathrm{P}\right)$ samples were not significantly different $(\mathrm{P}<0.05)$ across all eight generations and apparent attenuation remained stable between $56.92 \pm 3.49 \%$ and $67.96 \pm 5.92 \%$. Medium gravity $\left(14^{\circ} \mathrm{P}\right)$ fermentations experienced a peak in apparent attenuation $(69.54$ $\pm 3.51 \%$ ) during the first generation. The generations following had lower apparent attenuation but were not significantly different $(\mathrm{P}<0.05)$ from each other. These 
remained stable between $57.04 \pm 2.88 \%$ and $64.17 \pm 1.84 \%$. High gravity $\left(18{ }^{\circ} \mathrm{P}\right)$

fermentations experienced the most severe change in apparent attenuation. The peak was $72.17 \pm 0.96 \%$ after the first generation and this was significantly different $(\mathrm{P}<0.05)$ from the following seven generations. Apparent attenuation dropped significantly in the second generation and remained at this lower level. The lowest recorded was $48.00 \pm$ $1.16 \%$ after the sixth generation.

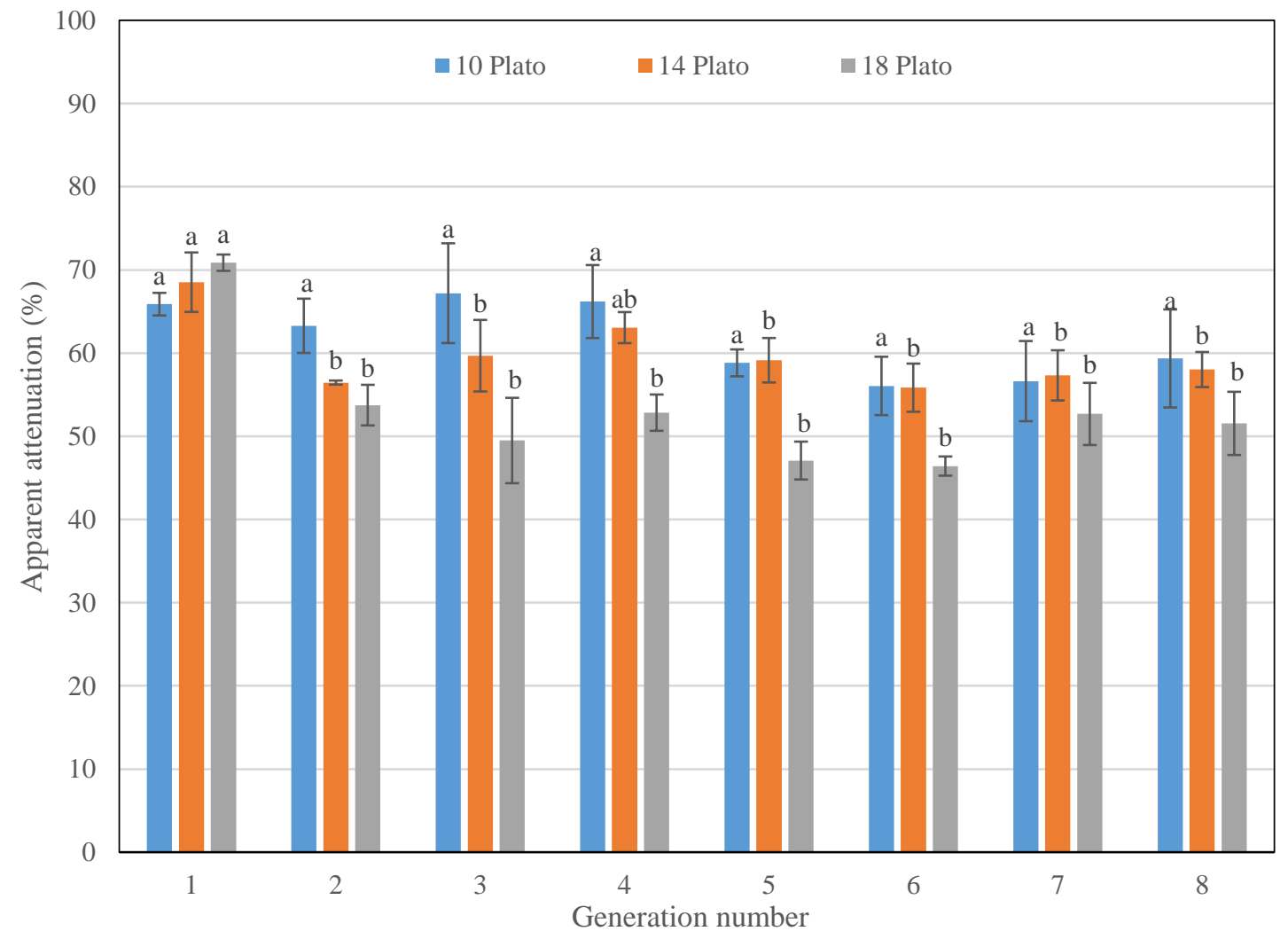

Figure 2: Apparent attenuation of Saccharomyces cerevisiae after five day successive fermentations with low $\left(10{ }^{\circ} \mathrm{P}\right)$ medium $\left(14^{\circ} \mathrm{P}\right)$ and high $\left(18{ }^{\circ} \mathrm{P}\right)$ initial gravities. Means are expressed with \pm standard deviation. All samples performed in triplicate. Values of the same gravity level that share a letter are not significantly $(\mathrm{P} \leq$ $0.05)$ different.

Though a formal sensory evaluation was not completed, it was noted that the stereotypical buttery scent of diacetyl was observed in the sixth, seventh, and eighth generations of the high gravity samples. Accumulation of diacetyl is often indicative of 
cellular stress and underperformance, and this has been reported in the literature in a previous study of repitching yeast in high gravity fermentations (Pires et al., 2014). These notes were not detected in the low and medium gravity fermentations at these generations. It is recommended for future studies to incorporate a full sensory evaluation as well as a GC/MS analysis in order to quantify the amount of diacetyl at the end of fermentation. High gravity fermentations may require more time to reach the desired apparent attenuation. However, given the results of the viability study, it is likely that these later generation fermentations have slowed and more time could lead to greater quantities of off notes (Casey et al., 1983). The slowed fermentation could possibly be indicated by the low apparent attenuations at the end of the cycle. It is possible that if given more time, the fermentation would continue and apparent attenuation would increase. In future experiments it would be advised to investigate fermentation time as an additional variable.

The results of the apparent attenuation analysis were consistent with what was found in the viability assessment. Lower gravity fermentations did not negatively impact yeast health and performance as did the high gravity fermentations over the eight generations. This is likely due to the combination of stress due to the initial high osmotic pressure induced by elevated starting gravities as well and the accumulation of stress from repeated exposure to higher levels of ethanol at the end of fermentation. Findings of this study were in line with what was reported in previous experiments (Jenkins et al., 2003; Lentini et al., 2003; Stewart, 2014). 


\subsubsection{Effect of high gravity successive fermentations on yeast viability}

The relative health of a yeast culture for fermentation is determined by its viability (Blake, et al., 2015). This is the first parameter brewers will monitor for quality purposes. Viability was measured by the methylene blue method (American Society of Brewing Chemists, 2005), which is standard in the brewing industry. It has been reported in previous studies that when viability falls below $85 \%$, yeast growth rates, flocculation rates, and fermentation performance are negatively impacted. Common flavor notes attributed to poor yeast health and cellular stress such as diacetyl and acetaldehyde are detected at this lower level of viability (Powel, et al., 2003, Verbelen et al., 2009). Additionally, the accuracy of this method has been shown to decline as viability drops below $85 \%$ (Boyd et al., 2003). For these reasons, it was determined that it would not be recommended to repitch yeast after viability falls below $85 \%$ in this experiment.

Overall viability fluctuated throughout the experiment for all gravity levels (Table 3) as generation number increased. Variation in standard deviation as well as occasional high standard deviations were also observed. However when comparing these results to previous studies, it appeared to be due to the nature of variability within microbiological systems (Erten et al., 2007). In future studies including more replicates for each treatment could potentially reduce this variability.

Low $\left(10^{\circ} \mathrm{P}\right)$ gravity samples exhibited higher viabilities throughout all generations when compared to the medium $\left(14{ }^{\circ} \mathrm{P}\right)$ and high $\left(18{ }^{\circ} \mathrm{P}\right)$ gravity samples. This was to be expected as it has been reported in previous studies that yeast harvested from lower gravity fermentations exhibit fewer signs of cellular stress, including higher viabilities, when compared to high gravity fermentations (Stewart 2014; Powell et al., 2007; Pratt, 
2007). Yeast viability in these low gravity fermentations were not significantly different $(\mathrm{P}<0.05)$ throughout the experiment and also remained above the $85 \%$ cutoff for the repitching recommendation determined throughout the eight generations.

Table 3: Viability (\%) of Saccharomyces cerevisiae after 5 days of fermentation at $21^{\circ} \mathrm{C}$ with low $\left(10{ }^{\circ} \mathrm{P}\right)$ medium $\left(14^{\circ} \mathrm{P}\right)$ and high $\left(18{ }^{\circ} \mathrm{P}\right)$ initial gravities. Means are expressed with \pm standard deviation. All samples performed in triplicate. Values in columns with the same letter are not significantly $(\mathrm{P} \leq 0.05)$ different.

\begin{tabular}{cccc}
\hline & \multicolumn{3}{c}{ Viability $\mathbf{\%})$} \\
\hline Generation & $\mathbf{1 0}^{\circ} \mathrm{P}$ & $\mathbf{1 4}^{\circ} \mathrm{P}$ & $\mathbf{1 8}^{\circ} \mathrm{P}$ \\
$\mathbf{1}$ & $87.51 \pm 1.70^{\mathrm{a}}$ & $93.40 \pm 1.86^{\mathrm{a}}$ & $92.96 \pm 3.46^{\mathrm{a}}$ \\
$\mathbf{2}$ & $86.74 \pm 2.84^{\mathrm{a}}$ & $89.27 \pm 0.46^{\mathrm{abc}}$ & $88.37 \pm 1.88^{\mathrm{abc}}$ \\
$\mathbf{3}$ & $85.30 \pm 2.86^{\mathrm{a}}$ & $84.12 \pm 1.41^{\mathrm{c}}$ & $86.78 \pm 3.02^{\mathrm{abcd}}$ \\
$\mathbf{4}$ & $89.74 \pm 6.39^{\mathrm{a}}$ & $85.33 \pm 2.86^{\mathrm{bc}}$ & $87.38 \pm 2.92^{\mathrm{abcd}}$ \\
$\mathbf{5}$ & $86.10 \pm 3.88^{\mathrm{a}}$ & $91.10 \pm 2.14^{\mathrm{ab}}$ & $89.28 \pm 3.02^{\mathrm{ab}}$ \\
$\mathbf{6}$ & $92.33 \pm 2.80^{\mathrm{a}}$ & $84.14 \pm 1.41^{\mathrm{c}}$ & $80.50 \pm 4.42^{\mathrm{bcd}}$ \\
$\mathbf{7}$ & $89.22 \pm 0.69^{\mathrm{a}}$ & $83.45 \pm 2.88^{\mathrm{c}}$ & $76.53 \pm 5.71^{\mathrm{d}}$ \\
$\mathbf{8}$ & $88.93 \pm 2.38^{\mathrm{a}}$ & $82.98 \pm 4.20^{\mathrm{c}}$ & $77.28 \pm 6.35^{\mathrm{cd}}$ \\
\hline
\end{tabular}

The viability of the medium $\left(14{ }^{\circ} \mathrm{P}\right)$ gravity samples remained above $85 \%$ for five generations. A drop in viability below the $85 \%$ cutoff occurred after three generations, though increased again in the fourth and fifth generations. In the sixth, seventh, and eighth generations, the viability of these medium gravity samples continued to decline. These final three generations were also significantly different $(\mathrm{P}<0.05)$ from all generations prior, with the exception of the third generation. It is possible that the drop below $85 \%$ viability in the third generation was due to experimental error and high variability within the sample since an increase in viability was observed in the generations following.

High $\left(18^{\circ} \mathrm{P}\right)$ gravity fermentations exhibited the most significant decline in yeast viability throughout the eight generations. Viability for these samples dropped below the $85 \%$ viability cutoff after five generations and continued to decrease in subsequent generations. Additionally the lowest viability observed in this study $(76.53 \pm 5.71 \%)$ 
occurred after the sixth generation for the high gravity samples. These results indicate that the yeast is struggling in its environment. This is perhaps due to the combination of higher osmotic pressure at the beginning of fermentation and the higher ethanol content at the end of fermentation.

Increased concentration of fermentable sugars in the wort produce higher levels of osmotic pressure on the yeast cells. Previous research by Zhuang et al. (2017) looked closely at the osmolality of high gravity wort and its effect on yeast physiology. A reduction in yeast viability was observed when cells were challenged with higher osmotic pressure. It was also found that increased osmotic pressure compromised the integrity of cellular membrane structure, either through direct damage or alterations as a specific stress response of the cell. When membrane fluidity is hindered fermentation efficiency is greatly affected fermentation efficiency as the rate of exchange of nutrients is vital for this process (Zhuang et al., 2017). It is likely that these effects are observed in the present study, as higher gravity fermentations resulted in yeast with lower viability.

\subsubsection{Alcohol by volume of high gravity successive fermentations}

In addition to higher osmotic pressure, yeast in higher gravity fermentations are subject to increased levels of ethanol at the end of fermentation. Ethanol is produced through the anaerobic consumption of glucose. Throughout the experiment the high gravity fermentations consistently produced more ethanol than observed in the low and medium gravity fermentations (Table 4). Ethanol produced in the low gravity fermentations remained between $3.24 \pm 0.27$ and $3.84 \pm 0.34 \%$. Values were not statistically significantly different $(\mathrm{P} \leq 0.05)$ over all generations. There was slightly more variation in the ethanol produced for the medium gravity fermentations and these 
values remained between $4.31 \pm 0.17$ and $5.49 \pm 0.28 \%$, with the highest value produced in the first generation and lowest in the second generation. In the generations following, ABV fluctuated though there was no clear pattern. The range for high gravity fermentations was $5.12 \pm 0.15$ to $7.76 \pm 0.16 \%$. The highest value of $\mathrm{ABV}$ was from the first generation and this was significantly different $(\mathrm{P} \leq 0.05)$ from all generations following. After this generation the amount of ethanol produced during fermentation decreased, though still remained higher than samples of the lower gravity levels.

Table 4: Alcohol by volume (\%) of Saccharomyces cerevisiae after 5 days of fermentation at $21^{\circ} \mathrm{C}$ with low $\left(10{ }^{\circ} \mathrm{P}\right)$ medium $\left(14^{\circ} \mathrm{P}\right)$ and high $\left(18{ }^{\circ} \mathrm{P}\right)$ initial gravities. Means are expressed with \pm standard deviation. All samples performed in triplicate. Values in columns with the same letter are not significantly $(\mathrm{P} \leq 0.05)$ different.

\begin{tabular}{cccc}
\hline & \multicolumn{3}{c}{ Alcohol by volume (\%) } \\
\hline Generation & $\mathbf{1 0}^{\circ} \mathrm{P}$ & $\mathbf{1 4}^{\circ} \mathrm{P}$ & $\mathbf{1 8}^{\circ} \mathrm{P}$ \\
$\mathbf{1}$ & $3.81 \pm 0.08^{\mathrm{a}}$ & $5.49 \pm 0.28^{\mathrm{a}}$ & $7.76 \pm 0.16^{\mathrm{a}}$ \\
$\mathbf{2}$ & $3.63 \pm 0.15^{\mathrm{a}}$ & $4.31 \pm 0.17^{\mathrm{c}}$ & $5.47 \pm 0.26^{\mathrm{b}}$ \\
$\mathbf{3}$ & $3.84 \pm 0.34^{\mathrm{a}}$ & $4.98 \pm 0.39^{\mathrm{abc}}$ & $5.49 \pm 0.58^{\mathrm{b}}$ \\
$\mathbf{4}$ & $3.76 \pm 0.19^{\mathrm{a}}$ & $5.05 \pm 0.13^{\mathrm{ab}}$ & $5.60 \pm 0.16^{\mathrm{b}}$ \\
$\mathbf{5}$ & $3.41 \pm 0.16^{\mathrm{a}}$ & $4.94 \pm 0.23^{\mathrm{abc}}$ & $5.27 \pm 0.24^{\mathrm{b}}$ \\
$\mathbf{6}$ & $3.29 \pm 0.20^{\mathrm{a}}$ & $4.62 \pm 0.28^{\mathrm{bc}}$ & $5.12 \pm 0.15^{\mathrm{b}}$ \\
$\mathbf{7}$ & $3.24 \pm 0.27^{\mathrm{a}}$ & $4.71 \pm 0.28^{\mathrm{bc}}$ & $5.76 \pm 0.30^{\mathrm{b}}$ \\
$\mathbf{8}$ & $3.41 \pm 0.30^{\mathrm{a}}$ & $4.70 \pm 0.21^{\mathrm{bc}}$ & $5.61 \pm 0.42^{\mathrm{b}}$ \\
\hline
\end{tabular}

Ethanol is toxic to yeast and exposure to it over time during the fermentation process negatively impacts the physiological status of the yeast cells (Kobayashi et al., 2007). In previous research it was found that cropped slurries from successive fermentations exhibited highly variable viability and flocculation rates. It was determined that in addition to the stress from successive fermentations, repeated exposure to high ethanol content at the end of fermentation caused an accumulation of stress within the cells which further lead to undesirable fermentation outcomes (Smart et al., 1996). 


\section{$\underline{\text { 2.3.1.4 Discussion }}$}

Under the conditions in this experiment, low gravity fermentations would be recommended for repitching up to eight though possibly more generations based on the viability observations alone. Medium gravity fermentations would be recommended for repitching for three generations. However, due to the increase in viability observed in the fourth generation, it is possible that the medium gravity fermentations could be repitched up to five generations. Yeast harvested from high gravity fermentations could be repitched up to five times. Yeast with viability below the threshold $(85 \%)$ set for this experiment exhibit traits that are indicative of cellular stress such as incomplete fermentations, presence of diacetyl, and poor flocculation rates. Repitching beyond the recommendations for these conditions could result in a lower quality beer due to poor fermentation performance, mutations, and undesirable flavor characteristics as indicated by previous studies.

The viability and fermentation performance results of this experiment are similar to those reported in previous studies on the effects of repitching with high gravity fermentations. Repeated exposure to high osmotic pressure and ethanol damage the cells, and this damage is more apparent as generation number increases (Jenkins et al., 2003). This damage can eventually lead to genetic mutations that can potentially give rise to unpredictable and undesirable fermentation outcomes (Jenkins et al., 2009). One of these undesirable byproducts, diacetyl, is present in successive fermentations of high gravity wort. This is likely a symptom of slowed or incomplete fermentations. Its concentration has been observed in previous research to increase as generation number increases, 
indicating that this stress injury cycle does in fact have negative implications for yeast fermentation performance and viability (Pires et al., 2014).

\subsubsection{High IBU and high gravity successive fermentations}

The same methodology from the previous section was repeated with the addition of Isohop (30\% IAA) at concentrations to represent low (25) medium (50) and high (75) IBU levels. This was done at each of the gravity levels in order to determine the impact that both IBU and high gravity fermentations had on yeast performance and viability throughout repitching cycles. Samples were performed in triplicate at each gravity and IBU level.

\subsubsection{Effect of high IBU and high gravity successive fermentations on apparent} attenuation

Apparent attenuation was assessed at the end of the five day fermentation period and averages were reported. It was found that in general, the addition of iso-alpha acids resulted in lower apparent attenuation values when compared to the outcome of the initial high gravity experiment. The addition of iso-alpha acids also resulted in greater fluctuations and higher standard deviations than observed in the initial experiment.

It was unexpected that the low gravity $\left(10^{\circ} \mathrm{P}\right)$ fermentations (Figure 3$)$ would experience the most significant impact on apparent attenuation. The apparent attenuation for these samples reached as low as $33.07 \pm 2.42 \%, 35.91 \pm 10.05 \%$, and $37.20 \pm 6.91 \%$ for low, medium, and high IBU fermentations after the seventh generation. Comparatively, the apparent attenuations reported at the end of the low gravity fermentations were much lower than that of the high gravity fermentations. This could potentially be due to the cellular sequestration of hops acids as observed in previous 
research (Bryant et al., 2015; Hazelwood et al., 2009). In these studies it was found that post fermentation, yeast cells retain a portion of the hops acids within the vacuole and cell walls. It was found that this sequestration partially inhibits the transport of nutrients and bioavailability of zinc, an important cofactor for digestive enzymes (Hazelwood et al., 2009).

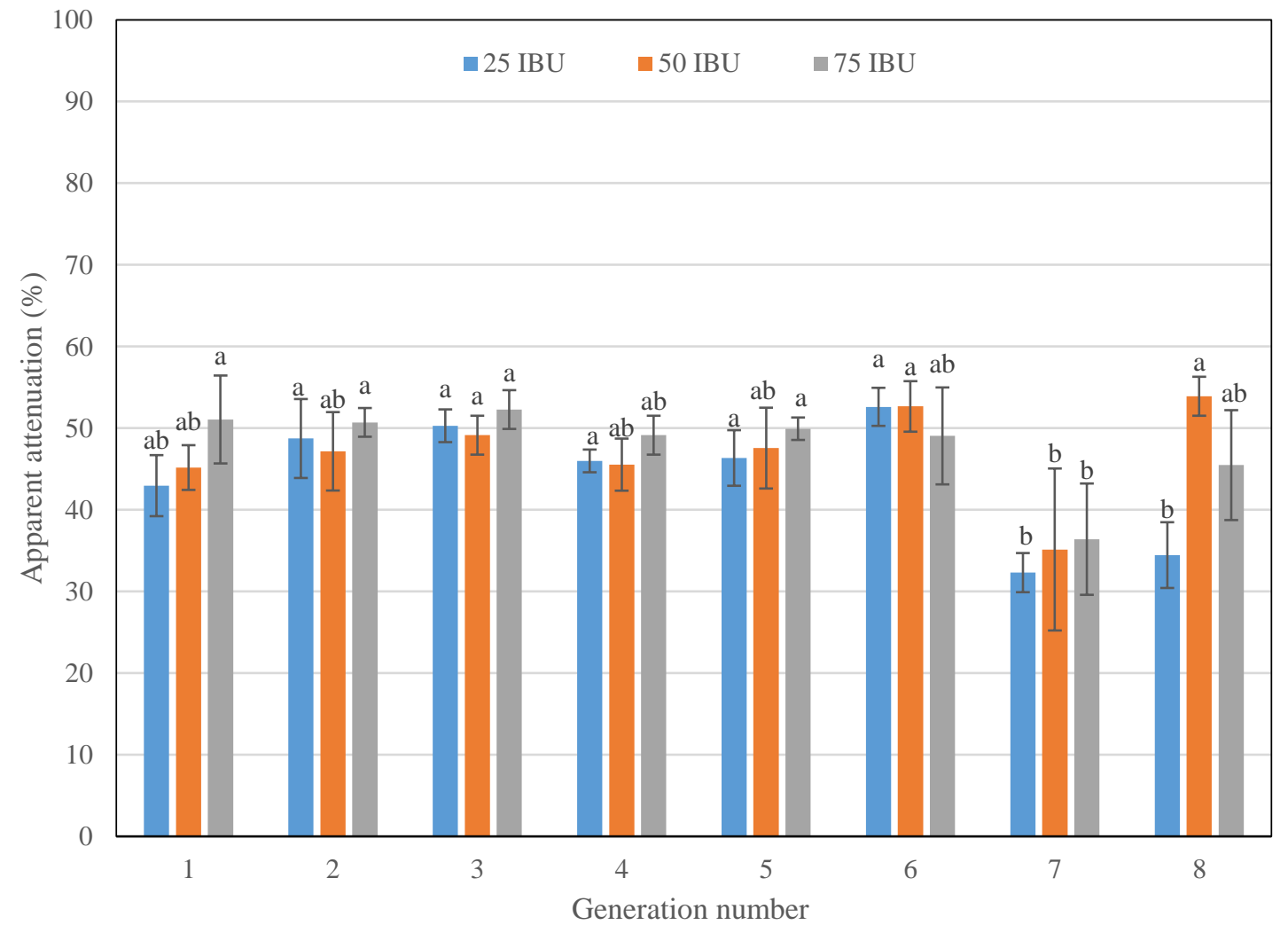

Figure 3: Apparent attenuation of Saccharomyces cerevisiae after five day successive low gravity fermentations $\left(10{ }^{\circ} \mathrm{P}\right)$ with low (25) medium (50) and high (75) IBU treatments. Means are expressed with \pm standard deviation. All samples performed in triplicate. Values of the same IBU level that share a letter are not significantly $(\mathrm{P} \leq 0.05)$ different.

It is possible that these results indicate that more cells were free of hops acids in the high gravity fermentations compared to the low gravity fermentations of the same IBU levels. While the pitch rate was the same for all gravity levels, the amount (mL) to inoculate was calculated using the initial gravity. This means that there were more cells 
per milliliter inoculated in the high gravity fermentations compared to the lower gravity fermentations. The amount of iso-alpha acids added was consistent throughout the experiment. The growing colony of yeast in the high gravity samples should be larger than that of the lower gravity samples. In theory with more cells in solution, there should be more cells that experience reduced or no sequestration of hops acids in the high gravity samples compared to the lower gravity samples. In future experiments it would be advised to investigate different pitching rates. Over-pitching in particular would be recommended as it has been stated in previous research that this can assist in overcoming common issues such as slow growth and fermentation rates (Jones et al., 2007; White et al., 2010)

Medium gravity $\left(14^{\circ} \mathrm{P}\right)$ fermentations experienced fluctuations of apparent attenuation at all IBU levels (Figure 4).. These results remained relatively high, and did not drop as significantly as observed in the low gravity $\left(10^{\circ} \mathrm{P}\right)$ fermentations. The lowest apparent attenuation reached for this gravity level was $47.18 \pm 4.18 \%$ after the sixth generation of the medium IBU level. When compared to results of the initial experiment, apparent attenuation was lower when any amount of iso-alpha acids were added. 


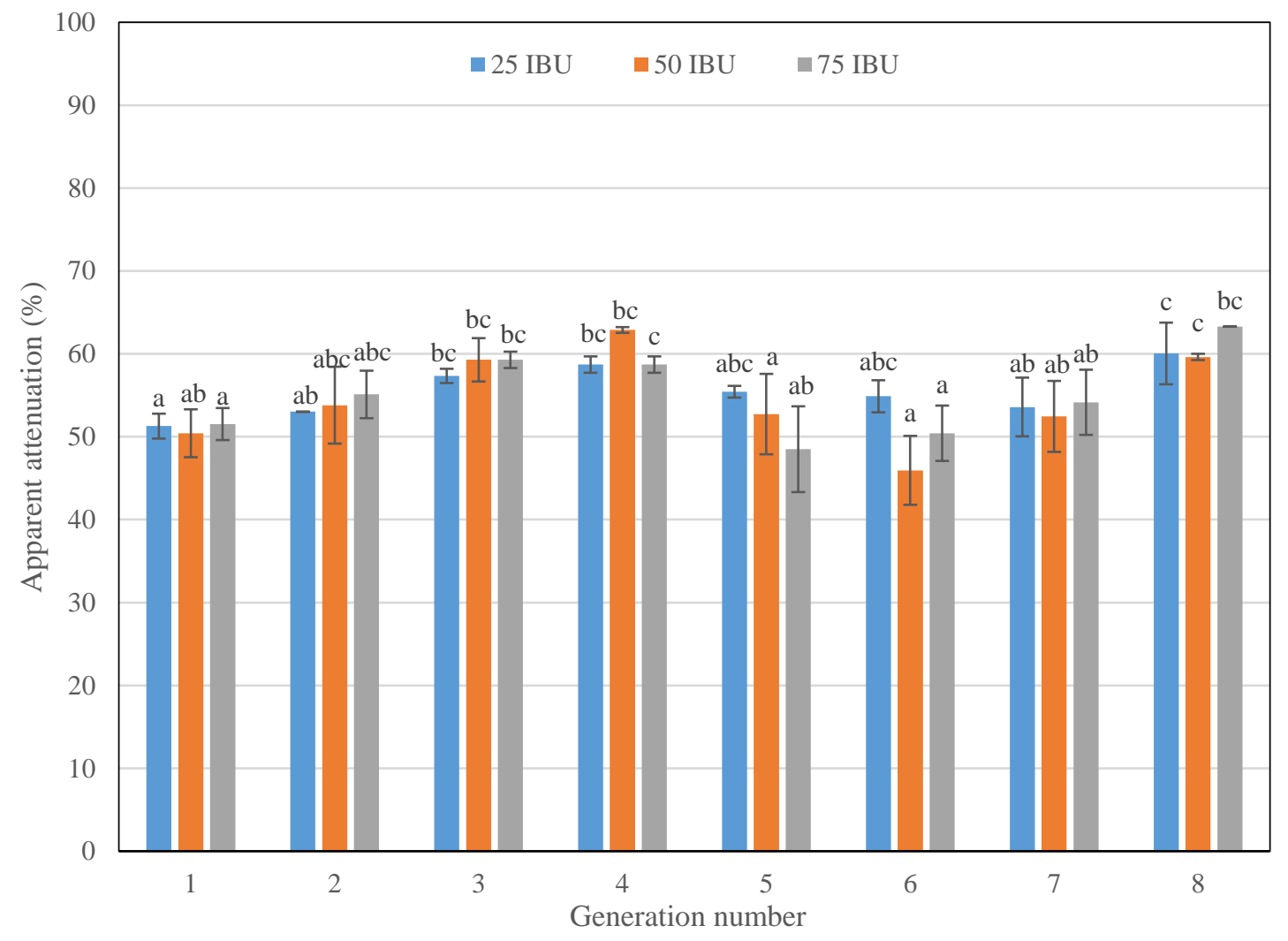

Figure 4: Apparent attenuation of Saccharomyces cerevisiae after five day successive medium gravity $\left(14^{\circ} \mathrm{P}\right)$ fermentations with low (25) medium (50) and high (75) IBU treatments. Means are expressed with \pm standard deviation. All samples performed in triplicate. Values of the same IBU level that share a letter are not significantly $(\mathrm{P} \leq 0.05)$ different.

Apparent attenuation of the high gravity $\left(18^{\circ} \mathrm{P}\right)$ fermentations remained relatively stable compared to the low and medium gravity fermentations (Figure 5). Over all eight generations, apparent attenuation of the medium IBU high gravity fermentations were not significantly different $(\mathrm{P} \leq 0.05)$. Low and high IBU fermentations at this gravity level experienced a slightly more variable range in apparent attenuation than the medium IBU samples. All IBU levels at this gravity experienced a decline in apparent attenuation after the second generation. This began to increase in the third generation for the low IBU and medium IBU samples. Apparent attenuation of the high IBU samples remained lower until after the sixth generation. 


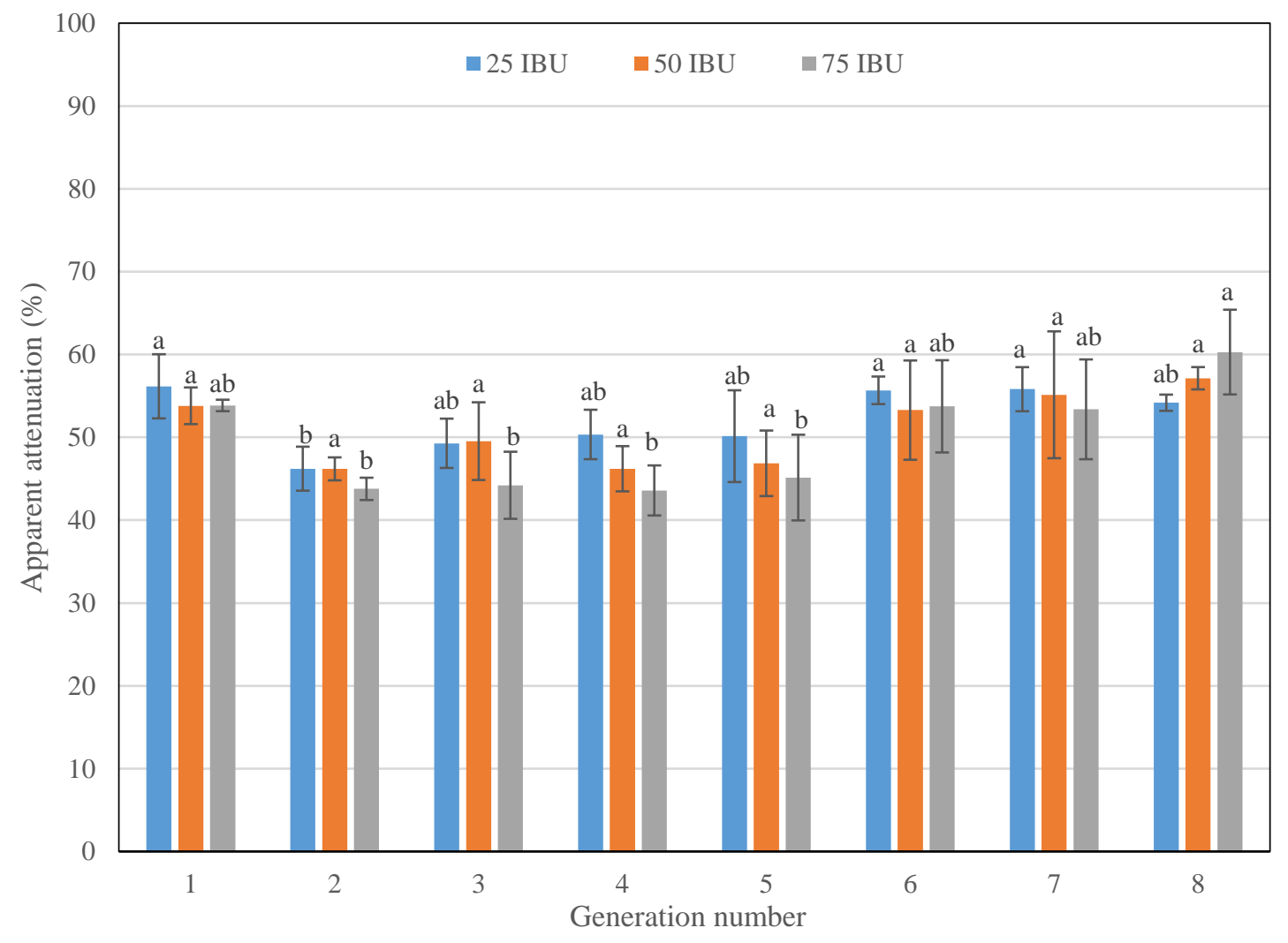

Figure 5: Apparent attenuation of Saccharomyces cerevisiae after five day successive high gravity $\left(18{ }^{\circ}\right.$ P) fermentations with low (25) medium (50) and high (75) IBU treatments. Means are expressed with \pm standard deviation. All samples performed in triplicate. Values of the same IBU level that share a letter are not significantly $(\mathrm{P} \leq 0.05)$ different.

There was a steady increase of apparent attenuation that occurred in the sixth, seventh, and eighth generations for all IBU levels of the medium and high gravity fermentations. This paired with the increasing viability reported in these generations indicate that perhaps the surviving yeast had adapted to its environment through mutation and natural selection. Since these mutations can result in undesirable results in the finished product and unpredictable fermentation outcomes, it would still not be advised to repitch beyond the recommendations made based on the viability assessments. 


\subsubsection{Effect of high IBU and high gravity successive fermentations on yeast viability}

Throughout the eight fermentation generations viability fluctuated similarly to the results of the initial high gravity experiment. Overall it was observed that viability decreased as generation number increased for samples of all IBU and gravity levels. Additionally, the same trends were observed in which the high gravity samples experienced the greatest decrease in viability. The viability of these samples fell below the $85 \%$ minimum generations sooner than their low gravity counterparts of the same IBU level. It was also observed that increased IBU level had a similar effect on yeast viability, where increasing this variable correlated to lower viabilities after the five day fermentation period when compared to the low IBU results. This was true for samples of all gravity levels.

The low gravity fermentations (Table 5) experienced the least significant impact on yeast viability throughout the eight generations. Low IBU fermentations at this gravity level experienced a minimal change in viability that was not significantly different ( $\mathrm{P}<0.05)$. Additionally, the viability of these samples remained above the $85 \%$ minimum and between $89.03 \pm 3.17 \%$ and $96.83 \pm 2.35 \%$. Medium (50) IBU samples at the low gravity level experienced a slightly greater decrease in viability than the low IBU samples over the eight generations. Viability dropped below the $85 \%$ minimum after the sixth generation and increased in the two generations following. The lowest point of viability was $84.59 \pm 2.20$ in the sixth generation and the highest point was $97.48 \pm$ $0.19 \%$ after the first generation. High (75) IBU samples at the low gravity level experienced the most significant decrease in viability over eight generations. Viability fell below the $85 \%$ minimum after the fifth generation and remained low in the 
generations following. The lowest point was after the seventh generation at $74.73 \pm$ $3.76 \%$ viability.

Table 5: Viability (\%) of Saccharomyces cerevisiae after 5 days of low gravity (10 $\left.{ }^{\circ} \mathrm{P}\right)$ fermentations at $21{ }^{\circ} \mathrm{C}$ with low (25) medium (50) and high (75) IBU treatments. Means are expressed with \pm standard deviation. All samples performed in triplicate. Values in columns with the same letter are not significantly $(\mathrm{P} \leq 0.05)$ different

\begin{tabular}{cccc}
\hline & \multicolumn{3}{c}{ Viability (\%) } \\
\hline Generation & $\mathbf{2 5} \mathbf{~ I B U}$ & $\mathbf{5 0 ~ I B U}$ & $\mathbf{7 5 ~ I B U}$ \\
\hline $\mathbf{1}$ & $95.60 \pm 2.53^{\mathrm{a}}$ & $97.48 \pm 0.19^{\mathrm{a}}$ & $94.48 \pm 0.93^{\mathrm{a}}$ \\
$\mathbf{2}$ & $96.83 \pm 2.35^{\mathrm{a}}$ & $91.69 \pm 2.91^{\mathrm{abc}}$ & $91.91 \pm 3.45^{\mathrm{a}}$ \\
$\mathbf{3}$ & $93.57 \pm 3.72^{\mathrm{a}}$ & $96.56 \pm 2.17^{\mathrm{ab}}$ & $91.85 \pm 1.92^{\mathrm{a}}$ \\
$\mathbf{4}$ & $96.06 \pm 2.84^{\mathrm{a}}$ & $91.45 \pm 4.16^{\mathrm{abc}}$ & $88.32 \pm 4.21^{\mathrm{ab}}$ \\
$\mathbf{5}$ & $90.38 \pm 3.37^{\mathrm{a}}$ & $90.52 \pm 1.02^{\mathrm{abc}}$ & $81.03 \pm 3.33^{\mathrm{bc}}$ \\
$\mathbf{6}$ & $89.43 \pm 5.31^{\mathrm{a}}$ & $84.59 \pm 2.20^{\mathrm{c}}$ & $78.25 \pm 3.56^{\mathrm{bc}}$ \\
$\mathbf{7}$ & $90.75 \pm 3.01^{\mathrm{a}}$ & $90.87 \pm 2.44^{\mathrm{abc}}$ & $74.73 \pm 3.76^{\mathrm{c}}$ \\
$\mathbf{8}$ & $89.03 \pm 3.17^{\mathrm{a}}$ & $88.23 \pm 5.13^{\mathrm{bc}}$ & $88.38 \pm 6.14^{\mathrm{ab}}$ \\
\hline
\end{tabular}

Viability of the medium gravity $\left(14^{\circ} \mathrm{P}\right)$ fermentations for all IBU levels fell below the threshold sooner than observed in the high gravity fermentations (Table 6). The low IBU fermentations fell below the minimum level recommended for repitching $(85 \%)$ to $77.52 \pm 2.59 \%$ after the fourth generation. This was the lowest viability observed for this this IBU and gravity level. Viability increased in the generations following though stayed below the threshold level for the rest of the experiment. Medium and high IBU samples fell below the minimum value for repitching $(85 \%)$ after the third fermentation generation. Viability continued to fall in the generations following, though increased after the seventh and eighth. The lowest viability point reached for the medium IBU fermentations at this gravity level was $74.65 \pm 6.91 \%$ after the fifth generation. The lowest viability reported of all gravity and IBU levels was $66.23 \pm 3.11 \%$ and recorded after the fourth generation of the medium gravity high IBU fermentations. 
Table 6: Viability (\%) of Saccharomyces cerevisiae after 5 days of medium gravity $\left(14{ }^{\circ} \mathrm{P}\right)$ fermentations at $21^{\circ} \mathrm{C}$ with low (25) medium (50) and high (75) IBU treatments. Means are expressed with \pm standard deviation. All samples performed in triplicate. Values in columns that share the same letter are not statistically significantly different using Tukey's test $(\mathrm{P}<0.05)$.

\begin{tabular}{cccc}
\hline & \multicolumn{3}{c}{ Viability (\%) } \\
\hline Generation & $\mathbf{2 5} \mathbf{~ I B U}$ & $\mathbf{5 0 ~ I B U}$ & $\mathbf{7 5 ~ I B U}$ \\
$\mathbf{1}$ & $93.92 \pm 4.30^{\mathrm{a}}$ & $95.58 \pm 3.16^{\mathrm{a}}$ & $92.98 \pm 0.94^{\mathrm{a}}$ \\
$\mathbf{2}$ & $92.48 \pm 3.77^{\mathrm{ab}}$ & $90.38 \pm 0.70^{\mathrm{ab}}$ & $89.39 \pm 3.65^{\mathrm{ab}}$ \\
$\mathbf{3}$ & $85.17 \pm 4.44^{\mathrm{abc}}$ & $83.32 \pm 4.56^{\mathrm{abc}}$ & $78.42 \pm 2.82^{\mathrm{bc}}$ \\
$\mathbf{4}$ & $77.52 \pm 2.59^{\mathrm{c}}$ & $76.16 \pm 7.96^{\mathrm{c}}$ & $66.23 \pm 3.11^{\mathrm{d}}$ \\
$\mathbf{5}$ & $82.11 \pm 4.43^{\mathrm{abc}}$ & $74.65 \pm 6.91^{\mathrm{c}}$ & $78.15 \pm 3.28^{\mathrm{c}}$ \\
$\mathbf{6}$ & $81.26 \pm 2.05^{\mathrm{abc}}$ & $80.21 \pm 3.83^{\mathrm{bc}}$ & $80.20 \pm 4.90^{\mathrm{bc}}$ \\
$\mathbf{7}$ & $83.77 \pm 8.74^{\mathrm{abc}}$ & $83.38 \pm 6.27^{\mathrm{abc}}$ & $87.30 \pm 3.12^{\mathrm{ab}}$ \\
$\mathbf{8}$ & $78.96 \pm 4.93^{\mathrm{bc}}$ & $86.03 \pm 1.70^{\mathrm{abc}}$ & $84.95 \pm 1.66^{\mathrm{abc}}$ \\
\hline
\end{tabular}

The results of the medium gravity fermentations in the IBU study were unexpected as it was found in the previous experiment and in the literature that the higher gravity fermentations tend to result in lower viabilities at completion (Jenkins et al., 2003; Lentini et al., 2003; Stewart 2014). Another explanation could be in the cell density of the fermentations. Pitch rate of these fermentations remained the same, though the calculation for the amount of cells to pitch was based on initial starting gravity. This means that the high gravity fermentations began with more cells in solution than the low and medium gravity fermentations. It was found in previous research that yeast cells experience retention of iso-alpha acids in their cell wall membrane and vacuole (Hazelwood et al., 2009). It is possible that with more cells in solution to absorb the impact of this sequestration of iso-alpha acids, the higher gravity fermentations were able to sustain cellular functions more effectively than the medium and low gravity counterparts at the high IBU level. This impact of iso-alpha acids on the low gravity fermentations was more evident in the apparent attenuation than viability, where it sharply declined below $40 \%$ for all IBU levels after the seventh generation. It would be 
recommended to investigate different pitch rates and cell densities for future studies under these conditions.

For the high gravity $\left(18^{\circ} \mathrm{P}\right)$ fermentation studies, the viability fell below the $85 \%$ minimum after four generations for all IBU levels. These continued to decline in the generations following, then increased steadily after the seventh and eighth generations. The lowest point reached for the high gravity low IBU fermentations was $78.86 \pm 5.17 \%$ after the sixth generation and the highest was $94.09 \pm 0.76 \%$ after the first generation. Medium IBU fermentations at this gravity level experienced the greatest decline in viability, reaching $73.22 \pm 3.06 \% \%$ after the sixth generation. The lowest viability for high IBU fermentations at this gravity level was $74.65 \pm 7.25 \%$ after the fourth generation.

Table 7: Viability (\%) of Saccharomyces cerevisiae after 5 days of high gravity (18 ${ }^{\circ}$ P) fermentations at $21{ }^{\circ} \mathrm{C}$ with low (25) medium (50) and high (75) IBU treatments. Means are expressed with \pm standard deviation. All samples performed in triplicate. Values in columns that share the same letter are not statistically significantly different using Tukey's test $(\mathrm{P}<0.05)$.

\begin{tabular}{cccc}
\hline & \multicolumn{3}{c}{ Viability (\%) } \\
\hline Generation & $\mathbf{2 5} \mathbf{~ I B U}$ & $\mathbf{5 0 ~ I B U}$ & $\mathbf{7 5 ~ I B U}$ \\
$\mathbf{1}$ & $94.09 \pm 0.76^{\mathrm{a}}$ & $92.10 \pm 3.20^{\mathrm{a}}$ & $96.04 \pm 1.34^{\mathrm{a}}$ \\
$\mathbf{2}$ & $90.58 \pm 2.50^{\mathrm{ab}}$ & $88.83 \pm 6.29^{\mathrm{ab}}$ & $88.46 \pm 4.30^{\mathrm{ab}}$ \\
$\mathbf{3}$ & $85.74 \pm 3.34^{\mathrm{abc}}$ & $85.41 \pm 7.25^{\mathrm{ab}}$ & $86.92 \pm 6.49^{\mathrm{abc}}$ \\
$\mathbf{4}$ & $80.81 \pm 5.77^{\mathrm{bc}}$ & $82.45 \pm 2.11^{\mathrm{abc}}$ & $74.65 \pm 7.25^{\mathrm{c}}$ \\
$\mathbf{5}$ & $80.51 \pm 5.17^{\mathrm{bc}}$ & $78.37 \pm 4.24^{\mathrm{bc}}$ & $77.07 \pm 2.78^{\mathrm{bc}}$ \\
$\mathbf{6}$ & $78.86 \pm 5.17^{\mathrm{c}}$ & $73.22 \pm 3.06^{\mathrm{c}}$ & $77.31 \pm 5.69^{\mathrm{bc}}$ \\
$\mathbf{7}$ & $80.12 \pm 1.77^{\mathrm{bc}}$ & $80.72 \pm 3.07^{\mathrm{abc}}$ & $79.16 \pm 2.26^{\mathrm{bc}}$ \\
$\mathbf{8}$ & $84.07 \pm 1.47^{\mathrm{abc}}$ & $80.96 \pm 1.84^{\mathrm{abc}}$ & $85.33 \pm 1.40^{\mathrm{abc}}$ \\
\hline
\end{tabular}

\section{$\underline{\text { 2.3.2.3 Alcohol by volume }}$}

Fermentations with different IBU treatments exhibited lower ABV values than what was observed in the initial experiment with solely the different starting gravity treatments. This makes sense as the ABV level is calculated using the initial and final 
gravities. It was found that the addition of iso-alpha acids resulted in a reduced apparent attenuation of samples regardless of gravity level.

It was expected that the $\mathrm{ABV}$ content of the low gravity $\left(10^{\circ} \mathrm{P}\right)$ fermentations with different IBU treatments (Table 8) would be lower than the medium and high gravity fermentations with different IBU treatments. The ABV values observed in this experiment were lower compared to the $\mathrm{ABV}$ values reported in the initial study of the low gravity $\left(10^{\circ} \mathrm{P}\right)$ fermentations with no IBU treatment. Because of this, it is likely that the variable affecting yeast viability and fermentation performance over the repitching cycles in the low gravity samples is the IBU treatment rather than the ABV content.

Table 8: Alcohol by volume (\%) of Saccharomyces cerevisiae after 5 days of low gravity $\left(10{ }^{\circ} \mathrm{P}\right)$ fermentations at $21{ }^{\circ} \mathrm{C}$ with low (25) medium (50) and high (75) IBU treatments. Means are expressed with \pm standard deviation. All samples performed in triplicate. Values in columns with the same letter are not significantly $(\mathrm{P} \leq 0.05)$ different.

\begin{tabular}{cccc}
\hline & \multicolumn{3}{c}{ Alcohol by volume (\%) } \\
\hline Generation & $\mathbf{2 5} \mathbf{~ I B U}$ & $\mathbf{5 0 ~ I B U}$ & $\mathbf{7 5 ~ I B U}$ \\
$\mathbf{1}$ & $2.55 \pm 0.23^{\mathrm{a}}$ & $2.58 \pm 0.15^{\mathrm{ab}}$ & $2.98 \pm 0.30^{\mathrm{a}}$ \\
$\mathbf{2}$ & $2.85 \pm 0.27^{\mathrm{a}}$ & $2.72 \pm 0.27^{\mathrm{ab}}$ & $2.89 \pm 0.16^{\mathrm{ab}}$ \\
$\mathbf{3}$ & $2.89 \pm 0.15^{\mathrm{a}}$ & $2.80 \pm 0.13^{\mathrm{a}}$ & $2.98 \pm 0.21^{\mathrm{a}}$ \\
$\mathbf{4}$ & $2.68 \pm 0.14^{\mathrm{a}}$ & $2.58 \pm 0.20^{\mathrm{ab}}$ & $2.80 \pm 0.13^{\mathrm{ab}}$ \\
$\mathbf{5}$ & $2.67 \pm 0.23^{\mathrm{a}}$ & $2.72 \pm 0.27^{\mathrm{ab}}$ & $2.85 \pm 0.08^{\mathrm{ab}}$ \\
$\mathbf{6}$ & $3.07 \pm 0.13^{\mathrm{a}}$ & $3.02 \pm 0.20^{\mathrm{a}}$ & $2.80 \pm 0.40^{\mathrm{ab}}$ \\
$\mathbf{7}$ & $1.88 \pm 0.13^{\mathrm{b}}$ & $2.01 \pm 0.58^{\mathrm{b}}$ & $2.10 \pm 0.43^{\mathrm{b}}$ \\
$\mathbf{8}$ & $1.97 \pm 0.20^{\mathrm{b}}$ & $3.06 \pm 0.13^{\mathrm{a}}$ & $2.53 \pm 0.40^{\mathrm{ab}}$ \\
\hline
\end{tabular}

The ABV measured for the medium gravity $\left(14^{\circ} \mathrm{P}\right)$ fermentations with different IBU treatments were slightly lower than those observed in the initial high gravity experiment. However these values are 1 to $2 \%$ higher than what was observed for the low gravity fermentations with different IBU treatments. Medium gravity fermentations fell below the minimum viability (85\%) for repitching generations sooner than the low gravity fermentations with different IBU treatments. It is likely that both the alcohol 
content at the end of fermentation as well as the different IBU treatments are affecting yeast viability and fermentation performance throughout the repitching cycles.

Table 9: Alcohol by volume (\%) of Saccharomyces cerevisiae after 5 days of medium gravity $\left(14^{\circ} \mathrm{P}\right)$ fermentations at $21^{\circ} \mathrm{C}$ with low (25) medium (50) and high (75) IBU treatments. Means are expressed with \pm standard deviation. All samples performed in triplicate. Values in columns with the same letter are not significantly $(\mathrm{P} \leq$ $0.05)$ different.

\begin{tabular}{cccc}
\hline & \multicolumn{3}{c}{ Alcohol by volume (\%) } \\
\hline Generation & $\mathbf{2 5} \mathbf{~ I B U}$ & $\mathbf{5 0 ~ I B U}$ & $\mathbf{7 5 ~ I B U}$ \\
$\mathbf{1}$ & $4.32 \pm 0.07^{\mathrm{a}}$ & $4.28 \pm 0.23^{\mathrm{ab}}$ & $4.36 \pm 0.15^{\mathrm{ab}}$ \\
$\mathbf{2}$ & $4.40 \pm 0.00^{\mathrm{ab}}$ & $4.49 \pm 0.41^{\mathrm{abc}}$ & $4.68 \pm 0.27^{\mathrm{abc}}$ \\
$\mathbf{3}$ & $4.70 \pm 0.08^{\mathrm{abc}}$ & $4.88 \pm 0.20^{\mathrm{bc}}$ & $4.88 \pm 0.08^{\mathrm{bc}}$ \\
$\mathbf{4}$ & $4.84 \pm 0.08^{\mathrm{bc}}$ & $5.10 \pm 0.08^{\mathrm{c}}$ & $4.84 \pm 0.08^{\mathrm{bc}}$ \\
$\mathbf{5}$ & $4.68 \pm 0.14^{\mathrm{abc}}$ & $4.40 \pm 0.35^{\mathrm{abc}}$ & $4.04 \pm 0.41^{\mathrm{a}}$ \\
$\mathbf{6}$ & $4.63 \pm 0.15^{\mathrm{abc}}$ & $3.87 \pm 0.36^{\mathrm{a}}$ & $4.27 \pm 0.27^{\mathrm{ab}}$ \\
$\mathbf{7}$ & $4.44 \pm 0.28^{\mathrm{ab}}$ & $4.35 \pm 0.34^{\mathrm{abc}}$ & $4.49 \pm 0.31^{\mathrm{ab}}$ \\
$\mathbf{8}$ & $4.98 \pm 0.34^{\mathrm{c}}$ & $4.88 \pm 0.08^{\mathrm{bc}}$ & $5.19 \pm 0.00^{\mathrm{c}}$ \\
\hline
\end{tabular}

High gravity $\left(18^{\circ} \mathrm{P}\right)$ fermentations had the highest ABV content at the end of fermentation. These were slightly reduced compared to the initial experiment with no IBU treatment. The ABV of these samples remained between 0.5 and $1.5 \%$ higher than what was observed in the medium gravity samples with different IBU treatments. No clear pattern was observed over the eight repitching generations. The ABV did not fall below $5.12 \pm 0.23 \%, 5.18 \pm 0.29 \%$, and $4.89 \pm 0.42 \%$ for low, medium, and high IBU treatments respectively at this gravity level. These values were only slightly higher than those observed for the medium gravity fermentations with different IBU treatments. It is likely that in the high gravity fermentations as well that the ethanol content had a major effect on the yeast performance and viability throughout repitching cycles. 
Table 10: Alcohol by volume (\%) of Saccharomyces cerevisiae after 5 days of high gravity $\left(18{ }^{\circ} \mathrm{P}\right)$ fermentations at $21^{\circ} \mathrm{C}$ with low (25) medium (50) and high (75) IBU treatments. Means are expressed with \pm standard deviation. All samples performed in triplicate. Values in columns with the same letter are not significantly $(\mathrm{P} \leq 0.05)$ different.

\begin{tabular}{cccc}
\hline & \multicolumn{3}{c}{ Alcohol by volume (\%) } \\
\hline Generation & $\mathbf{2 5 ~ I B U}$ & $\mathbf{5 0 ~ I B U}$ & $\mathbf{7 5 ~ I B U}$ \\
$\mathbf{1}$ & $5.86 \pm 0.26^{\mathrm{ab}}$ & $5.63 \pm 0.25^{\mathrm{a}}$ & $5.58 \pm 0.17^{\mathrm{ab}}$ \\
$\mathbf{2}$ & $5.12 \pm 0.23^{\mathrm{b}}$ & $5.07 \pm 0.16^{\mathrm{a}}$ & $4.90 \pm 0.22^{\mathrm{b}}$ \\
$\mathbf{3}$ & $5.39 \pm 0.43^{\mathrm{ab}}$ & $5.44 \pm 0.48^{\mathrm{a}}$ & $4.89 \pm 0.42^{\mathrm{b}}$ \\
$\mathbf{4}$ & $5.64 \pm 0.35^{\mathrm{ab}}$ & $5.18 \pm 0.29^{\mathrm{a}}$ & $4.90 \pm 0.32^{\mathrm{b}}$ \\
$\mathbf{5}$ & $5.64 \pm 0.57^{\mathrm{ab}}$ & $5.33 \pm 0.42^{\mathrm{a}}$ & $5.14 \pm 0.55^{\mathrm{b}}$ \\
$\mathbf{6}$ & $5.97 \pm 0.22^{\mathrm{ab}}$ & $5.64 \pm 0.59^{\mathrm{a}}$ & $5.68 \pm 0.55^{\mathrm{ab}}$ \\
$\mathbf{7}$ & $6.23 \pm 0.27^{\mathrm{a}}$ & $6.19 \pm 0.80^{\mathrm{a}}$ & $6.01 \pm 0.63^{\mathrm{ab}}$ \\
$\mathbf{8}$ & $5.94 \pm 0.14^{\mathrm{ab}}$ & $6.21 \pm 0.14^{\mathrm{a}}$ & $6.52 \pm 0.51^{\mathrm{a}}$ \\
\hline
\end{tabular}

\subsubsection{Discussion}

Recommendations for how many times under conditions of this experiment yeast could be repitched were made based on the viability results (Table 11). The minimum viability required for eligibility to repitch the sample was $85 \%$. Once viability fell below this level, it would not be recommended to repitch the yeast, even if viability were to increase in the following generations. Previous studies have found that at these lower viabilities, yeast produce undesirable flavor compounds that are indicative of cellular stress and underperformance (Powel et al., 2003; Verbelen et al., 2009). Low gravity fermentations could be repitched eight, five, and four times at low, medium and high IBU levels, respectively. Medium gravity fermentations could be repitched three times for low IBU levels and twice for medium and high IBU levels. High gravity fermentations could be repitched three times for all IBU levels. While the medium gravity fermentations behaved unexpectedly, comparison of the low and high gravity fermentations gives a clearer picture that increasing one or both of these factors does have a negative effect on yeast viability. 
Table 11: Repitching recommendations for low $\left(10{ }^{\circ} \mathrm{P}\right)$, medium $\left(14{ }^{\circ} \mathrm{P}\right)$ and high $\left(18{ }^{\circ}\right.$ P) starting gravity fermentations with low (25) medium (50) and high (75) IBU treatments. Recommendations are based on viability results of this experiment. Minimum viability required for eligibility to repitch was $85 \%$.

\begin{tabular}{cccc}
\hline & \multicolumn{3}{c}{ IBU Treatment } \\
\hline Starting Gravity & $\mathbf{2 5}$ IBU & 50 IBU & $\mathbf{7 5}$ IBU \\
$\mathbf{1 0}$ & 8 & 5 & 4 \\
$\mathbf{1 4}$ & 3 & 2 & 2 \\
$\mathbf{1 8}$ & 3 & 3 & 3 \\
\hline
\end{tabular}

Though viability increased in generations following and in some cases above the minimum declared for this experiment, it would still not be recommended to repitch the cells after viability has dropped below $85 \%$. It is possible that the increase in viability observed could indicate that the yeast is adapting to the high stress environment through genetic drift due to mutations over time. In the brewing environment this can lead to undesirable fermentation outcomes and inconsistencies in the final product (Jenkins et al., 2003; Jenkins et al., 2009; Martin et al., 2003). It was noted that in later generations of this experiment for all gravity and IBU levels that a buttery scent typical of diacetyl was detected. However, a formal sensory test was not performed. It would be advised for future research to investigate these typical off notes typical of cellular stress further through sensory testing and instrumental analysis. 


\subsection{CONCLUSIONS}

The results of the initial experiment suggested that repitching induces a stress response cycle within the cell. Yeast harvested from higher gravity fermentations exhibited lower viability and underperforms when compared to yeast harvested from lower gravity fermentations. The decrease in both viability and apparent attenuation over the course of the experiment indicate that yeast harvested from higher gravity fermentations cannot carry out as many fermentation generations as yeast harvested from lower gravity fermentations. These findings were consistent with what was reported in previous studies.

The addition of iso-alpha acids resulted lower viability at the end of fermentation for all gravity levels over the eight repitching cycles. This impact was more significant as IBU level increased. Differences between the low and high gravity fermentations with iso-alpha acid additions suggest that increasing both gravity and IBU levels in tandem induce a greater stress response in the cells and further reduces the number of times yeast could be repitched. Medium gravity fermentations with iso-alpha acid additions did not behave as predicted. However, comparing these results to that of the initial experiment for the medium gravity level it is evident that the addition of iso-alpha acids induced more stress on the cells indicated by the lower viabilities.

It was unexpected that the lower gravity fermentations would report a much lower apparent attenuation than the high gravity fermentations at the end of the repitching cycles. It was also unexpected that the apparent attenuation of the high gravity 
fermentations remained relatively stable throughout the eight generations. The apparent attenuation results indicate that perhaps pitch rate and cell density could be a factor in overcoming the stress induced by high gravity and high IBU fermentations. 


\section{FUTURE RESEARCH}

This research indicated that increasing both starting gravity and IBU level have serious implications for yeast health and performance over continuous fermentations. A formal sensory study is needed in order to assess the organoleptic acceptability of repitched product at these levels. It is also recommended for this sensory study to be paired with a GC/MS analysis to quantify the levels of certain components indicative of yeast underperformance.

Investigation into the effect of pitch rate and cell density would be needed in order to assess if this also is a factor in yeast overcoming certain stressors. It would also be interesting to investigate the impact of zinc supplementation in high IBU fermentations over repitching cycles.

These fermentations were very small scale compared to what is actually performed in breweries. While these results do provide a general idea of what happens when these factors are adjusted, it would be recommended to repeat the study on a larger scale. These results could potentially help optimize brewery practices for maximum efficiency. 


\section{REFERENCES}

Almaguer, C., Schonberger, C., Gastl, M., Arendt, E.K., and Becker, T. 2014. Humulus lupulus - a story that begs to be told. A review. Journal of the Institute of Brewing \& Distilling. 120:289-314.

American Society of Brewing Chemists. 1996. Report of Subcommittee on Yeast Flocculation by Absorbance Method. Journal of the American Society of Brewing Chemists. 54:245-248.

American Society of Brewing Chemists. 2005. Yeast-3A Methylene blue dead yeast cell stain (International Method). 63:220.

American Society of Brewing Chemists. 2012. Methods of Analysis, 7th ed. Beer-23A Bitterness units (BU) (International Method). 23:1-4.

American Society of Brewing Chemists. 2012. Methods of Analysis, online. Beer Flavor Database. www.asbcnet.org/MOA/Flavors_Database.aspx (accessed August 6, 2018). St. Paul, MN

Bamforth, C. 2009. Beer: Tap into the art and science of brewing ( $3^{\text {rd }}$ ed.). Oxford University Press. New York, New York.

Barth, R. 2013. The chemistry of beer: The science in the suds. John Wiley \& Sons, Inc. Hoboken, New Jersey.

Boulton, C. and Quain, D. 2006. Brewing yeast and fermentation. Blackwell Science Ltd, a Blackwell Publishing company. Oxford, UK.

Brewers Association. 2017. The New Brewer: Annual Industry Review (Issue May/June). The Journal of the Brewers Association. 34(1).

Bryant, R.W. 2015. Characterization of hop acids in spent brewer's yeast from craft and multinational sources. Journal of the American Society of Brewing Chemists. 72(2):159-164.

Casey, G.P. and Ingledew, W.M. 1983. High-gravity brewing: Influence on pitching rate and wort gravity on early yeast viability. Journal of the American Society of Brewing Chemists. 41(4): 148-152.

Coote, N. and Kirsop, B.H. 1976. Factors responsible for the decrease in pH during beer fermentations. Journal of the Institute of Brewing. 83:149-153.

Cunningham, S. and Stewart, G. 2000. Acid washing and serial repitching a brewing ale strain of Saccharomyces cerevisiae in high gravity wort and the role of oxygenation conditions. Journal of the Institute of Brewing 106(6):389-402. 
Deans, K., Pinder, A., Catley, B. J. \& Hodgson, J. A. 1997. Effects of cone cropping and serial repitch on the distribution of cell ages in brewery yeast. Proceedings of the European Brewing Convention. 26:469-476.

Edgerton, J. 2005. The impact of bitterness on the viability of harvested yeast. Journal of the American Society of Brewing Chemists. 63(1):28-30.

Erten, H. Tanguler, H., and Cakiroz, H. 2007. The effect of pitching rate on fermentation and flavour compounds in high gravity brewing. Journal of the Institute of Brewing \& Distilling. 113(1):75-79.

Goiris K., Jaskula-Goiris, B., Syryn, E., Opstaele, F.V., De Rouck, C. Aerts, G., and De Cooman, L. 2014. The flavoring potential of hop polyphenols in beer. Journal of the American Society of Brewing Chemists. 72(2):135-142.

Hazelwood, L.A., Walsh, M.C., Pronk, J.T., Daran, J.M. 2009, Tolerance to hop iso- $\alpha-$ acids in yeast involves vacuolar sequestration, and active transport. Applied environmental Microbiology. doi:10.1128/AEM.01457-09

IRI Market Research. 2016. U.S. Beer Sales: Top Selling Craft Beer Styles. The Beer Connoisseur. Chicago, Illinois.

Jazwinski, S.M. 1990. An experimental system for the molecular analysis of the aging process: The budding yeast Saccharomyces cerevisiae. The Journals of Gerontology. 45:68-74.

Jenkins, C.L., Kennedy, A.I., Thurston, P., Hodgson, J.A., and Smart, K.A. 2003. Serial repitching fermentation performance and functional biomarkers. Brewing Yeast and Fermentation Performance. Second Edition. 257-271.

Jenkins, C.L., Laurence, S.J., Kennedy, A.I., Thurston P., Hodgson, J.A., and Smart, K.A. 2009. Incidence and formation of petite mutants in lager brewing yeast Saccharomyces cereviae (syn. S. pastorianusI) populations. Journal of the American Society of Brewing Chemists. 67(2):72-80.

Jin, Y.L. and Speers, A. 2000. Effect of environmental conditions on the flocculation of saccharomyces cerevisiae. Journal of the American Society of Brewing Chemists. 58(3):108-116.

Jurado, J. 2002. A pale reflection on ale perfection. The Brewer International. 2(12):21-30.

Kobayashi, M., Shimizu, H., Shioya, S. 2007. Physiological analysis of yeast cells by flow cytometry during serial-repitching of low malt beer fermentations. Journal of Bioscience and Bioengineering. 103(5):51-456.

Kim, J.H., Kim, J.H., Choi, E.J., Lee, S.J., Kwon, Y.A., Hong, K.W., and Kim, W.J. 2014. Multivariate analysis for feasibility of Korean six-row barleys for beer producing. Journal of the Institute of Brewing. 120:371-378. 
Layfield, J.B.and Sheppard, J.D. 2015. What brewers should know about viability, vitality, and overall brewing fitness: A mini-review. Master Brewers Association of the Americas. 52(3):132-140.

Lei, H., Xu, H., Feng, L., Yu, Z., Zhao, H., and Zhao, M. 2016. Fermentation performance of lager yeast in high gravity beer fermentations with different sugar supplementations. Journal of Bioscience and Bioengineering. 122(5):583-588.

Lentini, A., Rogers, P., Higgins, V., Dawes, I., Chandler, M., Stanley, G., and Chambers, P. 2003. The impact of ethanol stress on yeast physiology. Brewing Yeast and Fermentation Performance. Second Edition. 25-38.

Mallett, J. 2014. Malt: A practical guide from field to brewhouse. Brewers Publications: A division of the Brewers Association. Boulder, Colorado.

Martin, V., Quain, D.E., and Smart, K.A. 2003. Brewing yeast oxidative Responses: Impact of brewery handling. Brewing Yeast and Fermentation Performance. Second Edition. 61-73.

McLaughlin, I.R., Lederer, C., and Schellhammer, T.H. 2008. Bitterness-modifying properties of hop polyphenols extracted from spent hop material. Journal of the American Society of Brewing Chemists. 66:174-183

Meaden, P., Arneborg, N., Guldfeldt, L. U, Siegumfeldt, H and Jakobsen, M., Endocytosis and vacuolar morphology in Saccharomyces cerevisiae are altered in response to ethanol stress or heat shock. Yeast, 1999, 15, 1211-1222.

Mochaba, F., O'Connor-Cox, E. S. C., and Axcell, B. C. (1998). Practical procedures to measure yeast viability and vitality prior to pitching. Journal of the American Society of Brewing Chemists.56(1):1-6.

Ogle, M. 2006. Ambitious brew: The story of American beer. Harcourt Books. Orlando, Florida.

Papazian, C. 2013. The complete joy of homebrewing, fourth edition: Fully revised and updated. William Morrow Paperbacks. New York City, New York.

Pickerell, A.T.W., Hwang, A. and Axcell. B.C. 1991. Impact of yeast-handling procedures on beer flavor development during fermentation. Journal of the American Society of Brewing Chemists. 49(2): 87-92.

Pires, E.J., Teixeira, J.A., Branyik, T., Corte-Real, M., Brandao, T., and Vicente, A.A. 2014. High gravity primary continuous beer fermentation using flocculent yeast biomass. Journal of the Institute of Brewing and Distilling. 120:486-494.

Powell, C.D., Quain, D.E., and Smart, K.A. 2003. The impact of brewing yeast cell age on fermentation performance, attenuation, and flocculation. Federation of European Microbiological Societies: Yeast Research. 3:149-157. 
Powell, C.D. Diacetis, A.N. 2007. Long term serial repitching and the genetic and phenotypic stability of brewer's yeast. Journal of the Institute of Brewing \& Distilling. 113(1):67-74.

Praet, T. and Van Opstaele, F. 2016. Flavor activity of sesquiterpene oxidation products, formed upon lab-scale boiling of a hop essential oil-derived sesquiterpene hydrocarbon fraction (cv. Saaz). Journal of the American Society of Brewing Chemists. 74(1):65-76.

Pratt, P.L., Bryce, J.H., Stewart, G.G. 2007. The yeast vacuole - a scanning electron microscopic study during high gravity wort fermentations. Journal of the Institute of Brewing \& Distilling. 113(1):55-60.

Silva, D.P. Branyik, T., Dragone, G., Vicente, A.A., Teixeira, J.A., and Almeida e Silva, J.B. 2008. High gravity batch and continuous process for beer production: Evaluation of fermentation performance and beer quality. Chemical Papers. 62(1)34-41.

Speers, A., Forbes, H. 2015. Yeast: an overview. Brewing Microbiology. Woodhead publishing. Waltham, MA.

Srinivasan, V., Goldberg, D., Haas, G.J. 2004. Contributions to the antimicrobial spectrum of hop constituents. Economic Botany. 58:230-238.

Standridge, N. 1970. Evaluation of two-row and six-row malting barley. Brewers' Digest, 45(12), 58-60.

Stewart, G.G. 2014. Brewing Intensification. American society of Brewing Chemists. St. Paul, Minnesota.

Taidi, B., Kennedy, A.I., and Hodgson, J.A. 2003. Wort substitutes and yeast nutrition. Brewing Yeast and Fermentation Performance. Second Edition. 86-95.

Thevelein, J. M. \& Hohmann, S. 1995. Trehalose synthase: guard to the gate of glycolysis in yeast? Trends Biochemical Sciences. 20:3-10.

White, C. and Zainasheff, J. 2010. Yeast: The practical guide to beer fermentation. Brewers Publications: A division of the Brewers Association. Boulder, Colorado

Wiemken, A. 1990. Trehalose in yeast, stress protectant rather than reserve carbohydrate. Antonie van Leeuwenhock. 58(3):209-217.

Wightman, P., Quain, D. E. and Meaden, P. G. 1996. Analysis of production brewing strains of yeast by DNA fingerprinting. Letters in Applied Microbiology. 22:90-94.

Zhuang, S., Smart, K., and Powell, C. 2017. Impact of extracellular osmolality on Saccharomyces yeast populations during brewery fermentations. Journal of the American Society of Brewing Chemists. 75(3):244-254. 


\section{APENDICES}

Table A1: Recorded initial gravities of fermentations with target low $\left(10{ }^{\circ} \mathrm{P}\right)$ medium $\left(14{ }^{\circ} \mathbf{P}\right)$ and high $\left(18{ }^{\circ} \mathbf{P}\right)$ initial gravities. Means are expressed with \pm standard deviation. All samples performed in triplicate.

\begin{tabular}{cccc}
\hline & \multicolumn{3}{c}{ Initial Gravity $\left({ }^{\circ} \mathbf{P}\right)$} \\
\hline Generation & $\mathbf{1 0}^{\circ} \mathrm{P}$ & $\mathbf{1 4}^{\circ} \mathrm{P}$ & $\mathbf{1 8}^{\circ} \mathrm{P}$ \\
$\mathbf{1}$ & $10.71 \pm 0.00$ & $14.27 \pm 0.23$ & $18.57 \pm 0.13$ \\
$\mathbf{2}$ & $10.63 \pm 0.14$ & $13.56 \pm 0.41$ & $17.21 \pm 0.66$ \\
$\mathbf{3}$ & $10.63 \pm 0.14$ & $15.66 \pm 1.80$ & $18.35 \pm 0.13$ \\
$\mathbf{4}$ & $10.55 \pm 0.14$ & $14.19 \pm 0.13$ & $17.74 \pm 0.46$ \\
$\mathbf{5}$ & $10.71 \pm 0.25$ & $14.66 \pm 0.13$ & $18.42 \pm 0.00$ \\
$\mathbf{6}$ & $10.79 \pm 0.14$ & $14.51 \pm 0.24$ & $18.20 \pm 0.23$ \\
$\mathbf{7}$ & $10.55 \pm 0.14$ & $14.43 \pm 0.14$ & $18.20 \pm 0.23$ \\
$\mathbf{8}$ & $10.63 \pm 0.14$ & $14.27 \pm 0.24$ & $18.12 \pm 0.13$ \\
\hline
\end{tabular}

Table A2: Recorded initial gravities with target low $\left(10{ }^{\circ} \mathrm{P}\right)$ medium $\left(14{ }^{\circ} \mathrm{P}\right)$ and high $\left(18{ }^{\circ} \mathrm{P}\right)$ initial gravities and low (25) medium (50) and high (75) IBU treatments. Means are expressed with \pm standard deviation. All samples performed in triplicate.

\begin{tabular}{|c|c|c|c|}
\hline & \multicolumn{3}{|c|}{$10^{\circ} \mathrm{P}$} \\
\hline Generation & 25 IBU & 50 IBU & $75 \mathrm{IBU}$ \\
\hline 1 & $10.80 \pm 0.14$ & $10.47 \pm 0.00$ & $10.72 \pm 0.00$ \\
\hline 2 & $10.72 \pm 0.00$ & $10.56 \pm 0.14$ & $10.47 \pm 0.24$ \\
\hline 3 & $10.56 \pm 0.14$ & $10.47 \pm 0.00$ & $10.47 \pm 0.14$ \\
\hline 4 & $10.64 \pm 0.28$ & $10.39 \pm 0.14$ & $10.47 \pm 0.00$ \\
\hline 5 & $10.55 \pm 0.14$ & $10.47 \pm 0.00$ & $10.47 \pm 0.00$ \\
\hline 6 & $10.71 \pm 0.00$ & $10.56 \pm 0.14$ & $10.47 \pm 0.24$ \\
\hline 7 & $10.56 \pm 0.14$ & $10.39 \pm 0.14$ & $10.47 \pm 0.24$ \\
\hline \multirow[t]{2}{*}{8} & $10.39 \pm 0.14$ & $10.47 \pm 0.00$ & $10.23 \pm 0.24$ \\
\hline & \multicolumn{3}{|c|}{$14^{\circ} \mathbf{P}$} \\
\hline Generation & 25 IBU & 50 IBU & 75 IBU \\
\hline 1 & $14.66 \pm 0.14$ & $14.74 \pm 0.00$ & $14.74 \pm 0.00$ \\
\hline 2 & $14.51 \pm 0.00$ & $14.59 \pm 0.14$ & $14.82 \pm 0.14$ \\
\hline 3 & $14.43 \pm 0.14$ & $14.51 \pm 0.00$ & $14.51 \pm 0.00$ \\
\hline 4 & $14.51 \pm 0.00$ & $14.35 \pm 0.14$ & $14.51 \pm 0.00$ \\
\hline 5 & $14.74 \pm 0.23$ & $14.89 \pm 0.14$ & $14.51 \pm 0.00$ \\
\hline 6 & $14.74 \pm 0.00$ & $14.58 \pm 0.14$ & $14.74 \pm 0.00$ \\
\hline 7 & $14.51 \pm 0.00$ & $14.51 \pm 0.00$ & $14.51 \pm 0.00$ \\
\hline \multirow[t]{2}{*}{8} & $14.59 \pm 0.14$ & $14.43 \pm 0.14$ & $14.51 \pm 0.00$ \\
\hline & \multicolumn{3}{|c|}{$18^{\circ} \mathbf{P}$} \\
\hline Generation & $25 \mathrm{IBU}$ & $50 \mathrm{IBU}$ & 75 IBU \\
\hline 1 & $17.59 \pm 0.26$ & $17.59 \pm 0.30$ & $17.44 \pm 0.26$ \\
\hline 2 & $18.27 \pm 0.13$ & $18.12 \pm 0.13$ & $18.35 \pm 0.26$ \\
\hline 3 & $18.12 \pm 0.35$ & $18.20 \pm 0.00$ & $18.20 \pm 0.00$ \\
\hline 4 & $18.50 \pm 0.13$ & $18.42 \pm 0.00$ & $18.42 \pm 0.00$ \\
\hline 5 & $18.58 \pm 0.13$ & $18.65 \pm 0.00$ & $18.65 \pm 0.00$ \\
\hline 6 & $17.97 \pm 0.23$ & $17.74 \pm 0.00$ & $17.74 \pm 0.00$ \\
\hline 7 & $18.58 \pm 0.14$ & $18.65 \pm 0.00$ & $18.65 \pm 0.00$ \\
\hline 8 & $18.27 \pm 0.13$ & $18.20 \pm 0.00$ & $18.20 \pm 0.00$ \\
\hline
\end{tabular}


Table A3: Recorded IBU values with targets of low (25), medium (50), and high (75) IBU and low $\left(10{ }^{\circ} \mathrm{P}\right)$ medium $\left(14{ }^{\circ} \mathrm{P}\right)$ and high $\left(18{ }^{\circ} \mathrm{P}\right)$ initial gravities. Means are expressed with \pm standard deviation. All samples performed in triplicate.

\begin{tabular}{|c|c|c|c|}
\hline & \multicolumn{3}{|c|}{$10^{\circ} \mathbf{P}$} \\
\hline Generation & 25 IBU & 50 IBU & 75 IBU \\
\hline 1 & $25.13 \pm 1.19$ & $45.63 \pm 1.17$ & $72.17 \pm 1.40$ \\
\hline 2 & $25.17 \pm 0.46$ & $44.23 \pm 1.70$ & $68.10 \pm 1.55$ \\
\hline 3 & $28.10 \pm 2.29$ & $43.33 \pm 1.72$ & $65.57 \pm 0.55$ \\
\hline 4 & $28.03 \pm 1.00$ & $51.53 \pm 0.80$ & $77.67 \pm 1.62$ \\
\hline 5 & $30.47 \pm 1.21$ & $53.13 \pm 0.64$ & $82.40 \pm 0.66$ \\
\hline 6 & $28.80 \pm 0.92$ & $56.03 \pm 1.89$ & $80.10 \pm 1.81$ \\
\hline 7 & $26.43 \pm 1.00$ & $51.53 \pm 1.11$ & $76.87 \pm 3.23$ \\
\hline \multirow[t]{2}{*}{8} & $25.47 \pm 1.51$ & $44.20 \pm 10.70$ & $72.53 \pm 3.87$ \\
\hline & \multicolumn{3}{|c|}{$14^{\circ} \mathrm{P}$} \\
\hline Generation & 25 IBU & 50 IBU & 75 IBU \\
\hline 1 & $25.90 \pm 0.95$ & $50.07 \pm 1.68$ & $69.70 \pm 3.69$ \\
\hline 2 & $27.63 \pm 1.60$ & $50.87 \pm 2.28$ & $76.87 \pm 0.98$ \\
\hline 3 & $25.30 \pm 0.76$ & $49.27 \pm 0.21$ & $73.03 \pm 0.84$ \\
\hline 4 & $22.80 \pm 0.36$ & $44.27 \pm 1.75$ & $65.23 \pm 1.91$ \\
\hline 5 & $23.43 \pm 1.30$ & $47.97 \pm 2.21$ & $71.00 \pm 2.11$ \\
\hline 6 & $22.67 \pm 1.32$ & $46.40 \pm 1.44$ & $67.67 \pm 3.94$ \\
\hline 7 & $25.27 \pm 0.91$ & $48.87 \pm 1.02$ & $72.50 \pm 1.87$ \\
\hline \multirow[t]{2}{*}{8} & $24.07 \pm 1.24$ & $49.13 \pm 2.87$ & $75.47 \pm 3.20$ \\
\hline & \multicolumn{3}{|c|}{$18^{\circ} \mathbf{P}$} \\
\hline Generation & $25 \mathrm{IBU}$ & $50 \mathrm{IBU}$ & $75 \mathrm{IBU}$ \\
\hline 1 & $33.90 \pm 0.30$ & $54.60 \pm 0.87$ & $81.90 \pm 1.54$ \\
\hline 2 & $29.00 \pm 2.45$ & $49.67 \pm 3.43$ & $70.27 \pm 1.27$ \\
\hline 3 & $28.10 \pm 1.23$ & $51.63 \pm 1.02$ & $74.83 \pm 2.28$ \\
\hline 4 & $29.07 \pm 0.49$ & $51.30 \pm 2.13$ & $75.77 \pm 2.72$ \\
\hline 5 & $26.00 \pm 0.40$ & $49.83 \pm 0.15$ & $72.40 \pm 0.66$ \\
\hline 6 & $26.57 \pm 0.59$ & $51.63 \pm 1.94$ & $70.33 \pm 1.33$ \\
\hline 7 & $25.63 \pm 0.32$ & $50.27 \pm 0.81$ & $70.03 \pm 1.16$ \\
\hline 8 & $25.87 \pm 1.03$ & $49.60 \pm 0.85$ & $73.00 \pm 2.10$ \\
\hline
\end{tabular}


Table A4: Apparent attenuation (\%) of Saccharomyces cerevisiae after 5 days of fermentation at $21^{\circ} \mathrm{C}$ with low $\left(10{ }^{\circ} \mathrm{P}\right)$ medium $\left(14^{\circ} \mathrm{P}\right)$ and high $\left(18{ }^{\circ} \mathrm{P}\right)$ initial gravities. Means are expressed with \pm standard deviation. All samples performed in triplicate. Values in columns that share the same letter are not statistically significantly (p $\leq 0.05)$ different.

\begin{tabular}{cccc}
\hline & \multicolumn{3}{c}{ Apparent attenuation (\%) } \\
\hline Generation & $\mathbf{1 0}^{\circ} \mathrm{P}$ & $\mathbf{1 4}^{\circ} \mathrm{P}$ & $\mathbf{1 8}^{\circ} \mathrm{P}$ \\
$\mathbf{1}$ & $66.67 \pm 1.34^{\mathrm{a}}$ & $69.54 \pm 3.51^{\mathrm{a}}$ & $72.17 \pm 0.96^{\mathrm{a}}$ \\
$\mathbf{2}$ & $64.08 \pm 3.23^{\mathrm{a}}$ & $57.57 \pm 0.28^{\mathrm{b}}$ & $55.22 \pm 2.40^{\mathrm{b}}$ \\
$\mathbf{3}$ & $67.96 \pm 5.92^{\mathrm{a}}$ & $60.87 \pm 4.27^{\mathrm{b}}$ & $51.08 \pm 5.14^{\mathrm{b}}$ \\
$\mathbf{4}$ & $66.96 \pm 4.33^{\mathrm{a}}$ & $64.17 \pm 1.84^{\mathrm{b}}$ & $54.36 \pm 2.14^{\mathrm{b}}$ \\
$\mathbf{5}$ & $59.68 \pm 1.62^{\mathrm{a}}$ & $60.33 \pm 2.65^{\mathrm{b}}$ & $48.68 \pm 2.28^{\mathrm{b}}$ \\
$\mathbf{6}$ & $56.92 \pm 3.49^{\mathrm{a}}$ & $57.04 \pm 2.88^{\mathrm{b}}$ & $48.00 \pm 1.16^{\mathrm{b}}$ \\
$\mathbf{7}$ & $57.48 \pm 4.80^{\mathrm{a}}$ & $58.50 \pm 3.01^{\mathrm{b}}$ & $54.25 \pm 3.70^{\mathrm{b}}$ \\
$\mathbf{8}$ & $60.19 \pm 5.85^{\mathrm{a}}$ & $59.19 \pm 2.10^{\mathrm{b}}$ & $53.11 \pm 3.79^{\mathrm{b}}$ \\
\hline
\end{tabular}

Table A5: Apparent attenuation (\%) of Saccharomyces cerevisiae after 5 days of low gravity $\left(10{ }^{\circ} \mathrm{P}\right)$ fermentations at $21^{\circ} \mathrm{C}$ with low (25) medium (50) and high (75) IBU treatments. Means are expressed with \pm standard deviation. All samples performed in triplicate. Values in columns that share the same letter are not statistically significantly ( $\mathrm{p}$ $\leq 0.05)$ different.

\begin{tabular}{cccc}
\hline & \multicolumn{3}{c}{ Apparent attenuation (\%) } \\
\hline Generation & $\mathbf{2 5 ~ I B U}$ & $\mathbf{5 0 ~ I B U}$ & $\mathbf{7 5 ~ I B U}$ \\
\hline $\mathbf{1}$ & $43.83 \pm 3.76^{\mathrm{ab}}$ & $46.03 \pm 2.75^{\mathrm{ab}}$ & $51.94 \pm 5.37^{\mathrm{a}}$ \\
$\mathbf{2}$ & $49.61 \pm 4.84^{\mathrm{a}}$ & $48.03 \pm 4.81^{\mathrm{ab}}$ & $51.57 \pm 1.77^{\mathrm{a}}$ \\
$\mathbf{3}$ & $51.16 \pm 2.01^{\mathrm{a}}$ & $50.00 \pm 2.38^{\mathrm{a}}$ & $53.14 \pm 2.39^{\mathrm{a}}$ \\
$\mathbf{4}$ & $46.86 \pm 1.41^{\mathrm{a}}$ & $46.38 \pm 3.21^{\mathrm{ab}}$ & $50.00 \pm 2.38^{\mathrm{ab}}$ \\
$\mathbf{5}$ & $47.21 \pm 3.42^{\mathrm{a}}$ & $48.41 \pm 4.96^{\mathrm{ab}}$ & $50.79 \pm 1.38^{\mathrm{a}}$ \\
$\mathbf{6}$ & $53.49 \pm 2.33^{\mathrm{a}}$ & $53.53 \pm 3.10^{\mathrm{a}}$ & $49.91 \pm 5.96^{\mathrm{ab}}$ \\
$\mathbf{7}$ & $33.07 \pm 2.42^{\mathrm{b}}$ & $35.91 \pm 10.05^{\mathrm{b}}$ & $37.20 \pm 6.91^{\mathrm{b}}$ \\
$\mathbf{8}$ & $35.23 \pm 4.06^{\mathrm{b}}$ & $54.76 \pm 2.38^{\mathrm{a}}$ & $46.30 \pm 6.76^{\mathrm{ab}}$ \\
\hline
\end{tabular}

Table A6: Apparent attenuation (\%) of Saccharomyces cerevisiae after 5 days of medium gravity $\left(14^{\circ} \mathrm{P}\right)$ fermentations at $21^{\circ} \mathrm{C}$ with low (25) medium (50) and high (75) IBU treatments. Means are expressed with \pm standard deviation. All samples performed in triplicate. Values in columns that share the same letter are not statistically significantly $(\mathrm{p} \leq 0.05)$ different.

\begin{tabular}{cccc}
\hline & \multicolumn{3}{c}{ Apparent attenuation (\%) } \\
\hline Generation & $\mathbf{2 5 ~ I B U}$ & $\mathbf{5 0 ~ I B U}$ & $\mathbf{7 5 ~ I B U}$ \\
\hline $\mathbf{1}$ & $52.52 \pm 1.48^{\mathrm{a}}$ & $51.67 \pm 2.89^{\mathrm{a}}$ & $52.78 \pm 1.92^{\mathrm{ab}}$ \\
$\mathbf{2}$ & $54.24 \pm 0.00^{\mathrm{ab}}$ & $55.03 \pm 4.63^{\mathrm{abc}}$ & $56.34 \pm 2.86^{\mathrm{abc}}$ \\
$\mathbf{3}$ & $58.52 \pm 0.85^{\mathrm{bc}}$ & $60.45 \pm 2.59^{\mathrm{bc}}$ & $60.45 \pm 0.98^{\mathrm{bc}}$ \\
$\mathbf{4}$ & $59.89 \pm 0.98^{\mathrm{bc}}$ & $64.00 \pm 0.35^{\mathrm{c}}$ & $59.89 \pm 0.98^{\mathrm{bc}}$ \\
$\mathbf{5}$ & $56.66 \pm 0.72^{\mathrm{abc}}$ & $53.95 \pm 4.82^{\mathrm{ab}}$ & $49.72 \pm 5.18^{\mathrm{ab}}$ \\
$\mathbf{6}$ & $56.11 \pm 1.92^{\mathrm{abc}}$ & $47.18 \pm 4.18^{\mathrm{a}}$ & $51.67 \pm 3.33^{\mathrm{a}}$ \\
$\mathbf{7}$ & $54.80 \pm 3.53^{\mathrm{ab}}$ & $53.67 \pm 4.27^{\mathrm{ab}}$ & $55.37 \pm 3.91^{\mathrm{ab}}$ \\
$\mathbf{8}$ & $61.21 \pm 3.69^{\mathrm{c}}$ & $60.79 \pm 0.39^{\mathrm{bc}}$ & $64.41 \pm 0.00^{\mathrm{c}}$ \\
\hline
\end{tabular}


Table A7: Apparent attenuation (\%) of Saccharomyces cerevisiae after 5 days of high gravity $\left(18{ }^{\circ} \mathrm{P}\right)$ fermentations at $21^{\circ} \mathrm{C}$ with low (25) medium (50) and high (75) IBU treatments. Means are expressed with \pm standard deviation. All samples performed in triplicate. Values in columns that share the same letter are not statistically significantly $(\mathrm{p} \leq 0.05)$ different.

\begin{tabular}{|c|c|c|c|}
\hline & \multicolumn{3}{|c|}{ Apparent attenuation (\%) } \\
\hline Generation & 25 IBU & 50 IBU & 75 IBU \\
\hline 1 & $57.64 \pm 3.81^{\mathrm{a}}$ & $55.31 \pm 2.19^{\mathrm{a}}$ & $55.34 \pm 0.71^{\mathrm{ab}}$ \\
\hline 2 & $47.80 \pm 2.65^{\mathrm{b}}$ & $47.77 \pm 1.39^{\mathrm{a}}$ & $45.36 \pm 1.38^{\mathrm{b}}$ \\
\hline 3 & $50.85 \pm 3.01^{\mathrm{ab}}$ & $51.11 \pm 4.68^{\mathrm{a}}$ & $45.78 \pm 4.07^{\mathrm{b}}$ \\
\hline 4 & $51.95 \pm 2.99^{\mathrm{ab}}$ & $47.81 \pm 2.74^{\mathrm{a}}$ & $45.18 \pm 3.04^{\mathrm{b}}$ \\
\hline 5 & $51.75 \pm 5.53^{\mathrm{ab}}$ & $48.48 \pm 3.97^{\mathrm{a}}$ & $46.75 \pm 5.19^{b}$ \\
\hline 6 & $57.20 \pm 1.66^{\mathrm{a}}$ & $54.79 \pm 5.97^{\mathrm{a}}$ & $55.25 \pm 5.54^{\mathrm{ab}}$ \\
\hline 7 & $57.39 \pm 2.63^{\mathrm{a}}$ & $56.71 \pm 7.61^{\mathrm{a}}$ & $54.98 \pm 6.00^{\mathrm{ab}}$ \\
\hline 8 & $55.75 \pm 0.98^{\mathrm{ab}}$ & $58.67 \pm 1.33^{\mathrm{a}}$ & $61.78 \pm 5.05^{\mathrm{a}}$ \\
\hline
\end{tabular}

